\title{
ESTIMATION OF HYDRAULIC PROPERTY OF JOINTED ROCK MASS CONSIDERING EXCAVATION-INDUCED CHANGE IN PERMEABILITY OF EACH JOINTS
}



\begin{abstract}
Underground excavation can induce significant deformation of pre-existing joints in rock mass. Due to the sliding and opening of the joints, consequent changes in the flow characteristics of a jointed rock mass would be anticipated. In the present work, the finite element excavation analysis for a jointed rock mass and the finite element flow and transport analysis using the discrete joint network model are employed and combined so as to make it possible to evaluate excavation induced changes in flow properties of a jointed rock mass. A separate computational module connecting these two codes is incorporated to modify initially imposed transmissivities into the excavation induced ones considering the deformation of joints during an excavation. The effect of excavation on the flow properties is evaluated by including these excavation induced transmissivity changes of individual joints. The excavation induced transmissivities are calculated using the analytical approximation solution developed for flow through a single rock joint. The calculation of the excavation induced transmissivity involves the distributions of shear displacements and normal stresses around the excavation, and explicitly takes into account of the effect of surface geometric roughness. A test simulation for a deep underground repository is performed to demonstrate the typical results predicted in the proposed approach.
\end{abstract}

Key words: a single joint, discrete network model, EDZ, jointed rock mass, micromechanics, transmissivity (IGC: F4/G7/G13)

\section{INTRODUCTION}

As far as a crystalline rock is concerned, excavation induced change in flow properties of jointed rock mass within an Excavation Disturbed Zone (EDZ) is considered to be caused mainly by an opening or a closing of pre-existing joints due to the variation of the normal and the shear stresses acting on each joints (Kelsall et al., 1984). Therefore, a prediction of the excavation induced change in the permeability of a jointed rock mass is expected to include the stress dependent change in the transmissivity of pre-existing joints. It has been widely investigated and generally accepted that the transmissivity of a single rough rock joint is decreased by normal closure (Tsang and Witherspoon, 1981; Raven and Gale, 1985), but remarkably increased by shear dilation (Barton et al., 1985; Olsson and Brown, 1993). Recently, an order scaled increment of the permeability due to shear deformation is reported in a couple of laboratory measurements (Esaki et al., 1999; Chen et al., 2000). Shear-induced anisotropy as well as an order scaled increment in the transmissivity through a single rough rock joint has been recently reported (Gentier et al., 1997; Yeo et al., 1998). In their laboratory experiments of radial flow through a single rock joint, they demonstrated that flow is reoriented by shear displacement, and much predominant flow rate is observed to the direction perpendicular to the shear direction. The same tendency was also reproduced in several numerical studies for a linear rectangular flow (Kim, 2002; Meheust and Schmittbuhl, 2001). Even though the effect of both shear and normal deformation of individual joints is known significantly, the development of flow model for jointed rock mass, especially that which includes shear induced anisotropy in transmissivity, has been limited (Brown and Bruhn, 1998).

An international project has been working on predicting hydro-mechanically coupled behavior of jointed rock mass as well as in measuring in-situ data for underground disposal of high level nuclear wastes (Jing et al., 1999). Numerical works in the project can be divided into two distinct groups, depending on whether a jointed rock mass is modeled by an effective continuum model or a discrete network model (Hudson et al., 2001). In the effective continuum approach, the effects of joints in a calculational element are approximated by an effective anisotropic continuum block, so that the coupling is conducted in terms of hydro-mechanically correlated

Department of Civil Engineering, the University of Tokyo, 7-3-1 Hongo, Bunkyo-ku, Tokyo 113-8656, Japan (inoue@ohriki.t.u-tokyo.ac.jp). The manuscript for this paper was received for review on March 1, 2004; approved on September $28,2004$.

Written discussions on this paper should be submitted before November 1, 2005 to the Japanese Geotechnical Society, 4-38-2, Sengoku, Bunkyo-ku, Tokyo 112-0011, Japan. Upon request the closing date may be extended one month. 
variables within the flow governing equation. While, in the discrete network approach, individual joints are treated discretely, and each network joint is allowed to deform according to the variations in in-situ stress conditions. In a near field analysis, in which the repository and its surrounding area are the regions of interest such that the individual joints can be treated discretely, the discrete network model can be more effective (Council, 1996), if the fracture system geometry and properties can be reliably determined.

In most discrete network models, the transmissivity variation is considered to be caused only by the normal deformation of joints and is based on the Barton-Bandis model. However, shear as well as normal deformations can be commonly observed, particularly in deep underground locations in which extremely high compressive in-situ stresses are present. In that situation, using only the normal deformation, the increase of transmissivity can not be explained, since the joints are not allowed to expand due to surrounding bed rocks with high stiffness, even if the normal stress is relieved by the excavation.

The primary objective of this study is to clarify the change in the flow characteristics of a jointed rock mass due to a tunnel excavation, by considering the deformation of joints within a rock mass caused by a redistribution of in-situ stresses.

In the following section, the flow characteristics of a single rough rock joint under deformation is estimated analytically, and the analytical solution is validated by numerical simulations. Based on the understanding about the flow characteristics of a single joint, a method to evaluate the effect of excavation on the flow properties of a jointed rock mass is proposed by combining the stress analysis with an excavated tunnel and flow analysis using a discrete network model. Finally, typical predictions obtained in test simulations using the proposed approach are introduced.

\section{FLOW IN A SINGLE ROUGH ROCK JOINT}

Owing to the spatial distribution of the local apertures, it has been well known that flow in a single joint is tortuous and channelized (Tsang and Witherspoon, 1981; Tsang and Tsang, 1989; Moreno and Tsang, 1994). Furthermore, since the aperture distribution is changed by a normal or a shear deformation on a joint, the transmissivity of the joint is dependent highly on the deformation of the joint. Previous laboratory measurements have reported that joint transmissivity is decreased by a normal load (Tsang and Witherspoon, 1981; Raven and Gale, 1985; Barton et al., 1985), but increased by a shear displacement (Makurat et al., 1990; Pyrak-Nolte et al., 1990; Olsson and Brown, 1993). Shear-induced anisotropy in the joint transmissivity has been also observed in the numerical studies (Kim, 2002; Meheust and Schmittbuhl, 2001) as well as in the experimental measurements (Yeo et al., 1998; Gentier et al., 2001).

On investigating the excavation induced changes in the flow property of a jointed rock mass, the deformation

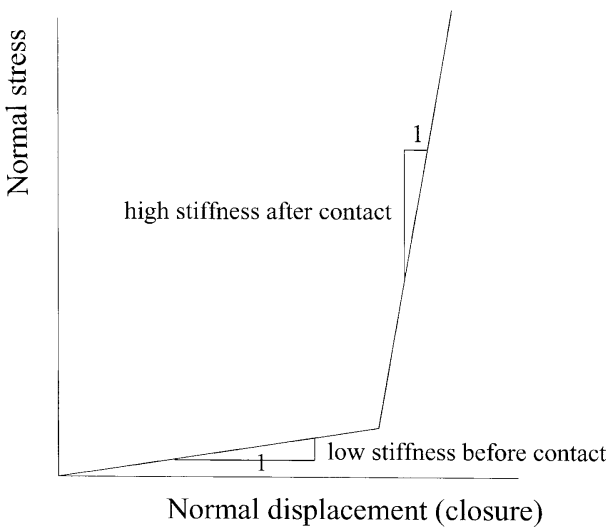

Fig. 1. Load-displacement curve used in the joint elements in order to simulate the deformation characteristic to the normal closure

dependent variation of the transmissivity of each joint inside the jointed rock mass is essential. Since an analytical approach can be more effective for obtaining the excavation induced change in transmissivity of each joint than experimental measurements or numerical estimations, the analytical approach for estimating flow through a single joint under deformation is addressed in this section after a brief description of the deformation induced change in the transmissivity obtained numerically.

\section{Numerical Approach for Flow through a Single Joint \\ Deformation and Aperture Distribution of a Joint}

Three dimensional finite element analysis is employed to show deformation characteristics of joints and to obtain aperture distribution of deforming joints. The analysis is conducted by introducing two dimensional plane joint elements between three dimensional elastic bodies. The 2-d plane joint elements have two distinct stiffnesses before and after the contact of two joint surfaces. Before two surfaces of the joints contact each other, the element can deform almost freely. On the contrary, once they contact each other, the deformation is restricted. A typical load-displacement curve for the 2-d plane elements is shown in Fig. 1.

Shear deformation is reproduced by sliding the upper block of the joints under controlled normal stress. In this stage, asperity degradations are neglected, for simplicity. Consequently, the shear dilation during the sliding is determined simply by the surface geometry of the joints.

Representative examples of aperture distributions for deforming joints obtained by the deformation analysis are shown in Figs. 2, 3, and 4. The analysis was performed using a grid of $41 \times 412$-d plane elements. The heights of the nodes were extracted from the measurement of a real rock joint surface geometry. The interval of the measurements was $1 \mathrm{~mm}$. Each 2-d plane elements are supported by 3 -d solid elements to consider the elastic deformation of the intact rock.

In Fig. 2, representative aperture distributions during a shear deformation are displayed. The upper figure (a) shows the aperture distribution for a zero shear displace- 




(a)



(b)

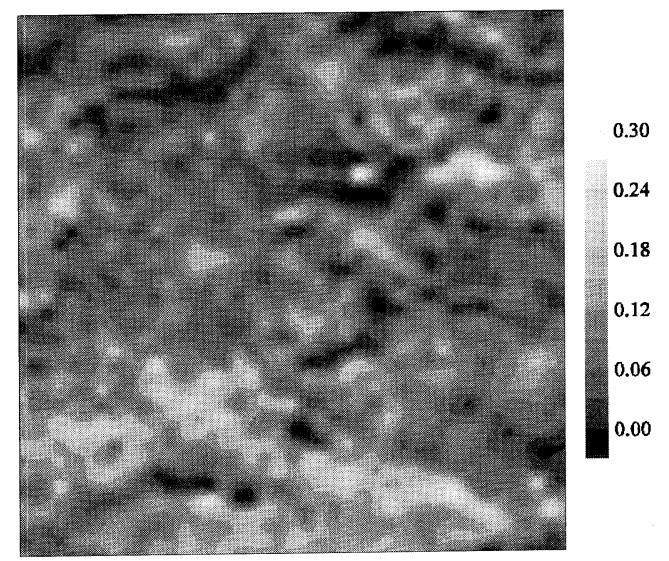

(c)

Fig. 2. Examples of aperture distributions during a shear deformation (The apertures are obtained as the separation distances between top and bottom nodes of the joint elements. Lighter color indicates higher aperture): (a) initial aperture distribution, (b) after $x$-directional sliding of $1 \mathrm{~mm}$ and (c) after $y$-directional sliding of $1 \mathrm{~mm}$

ment, and middle (b) and lower (c) figures show those after a shear displacement of $1 \mathrm{~mm}$ in $x$ - and $y$-direction, respectively. It is noted that the connected higher apertures originates along the direction perpendicular to the shear, regardless of sliding directions. Flow in the joint may occur through these connected apertures, thus it is not difficult to infer that flow in the direction perpendicular to the sliding direction may become much



(a)



(b)

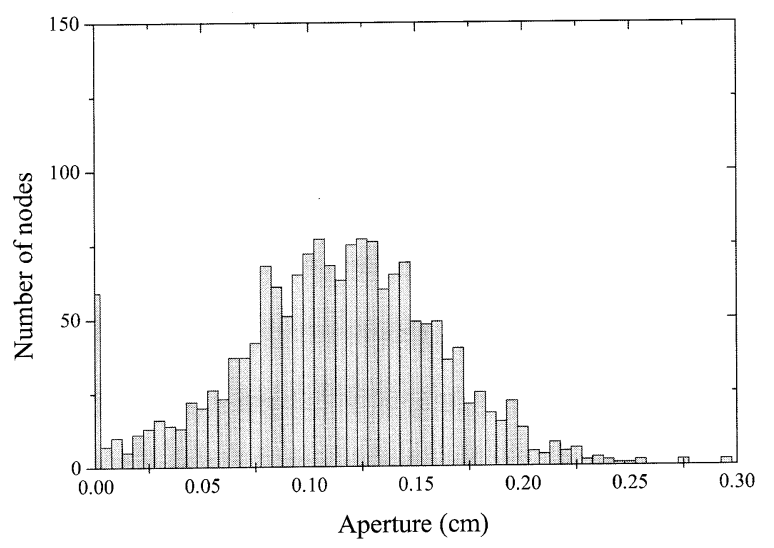

(c)

Fig. 3. Frequency histogram of aperture distributions during a shear deformation: (a) without shear displacement, (b) after the shear displacement of $1.0 \mathrm{~mm}$ and (c) after the shear displacement of $2.0 \mathrm{~mm}$

dominant and flow anisotropy will be induced during the shear deformation, which has been observed in the previous laboratory measurements (Yeo et al., 1998; Gentier et al., 1997).

Frequency histograms of a representative aperture distribution during a shear deformation and a normal stress are illustrated in Figs. 3 and 4, respectively. Although the shape of the histogram is highly dependent on the original shape of the real rock joint surface, the 


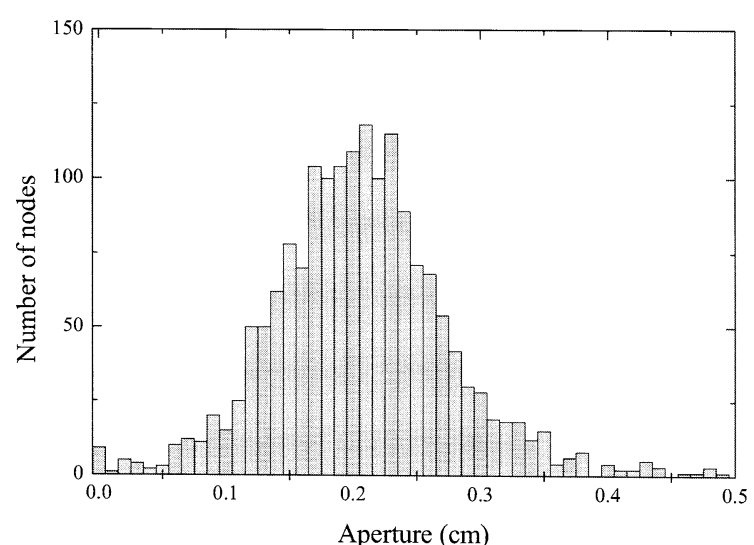

(a)

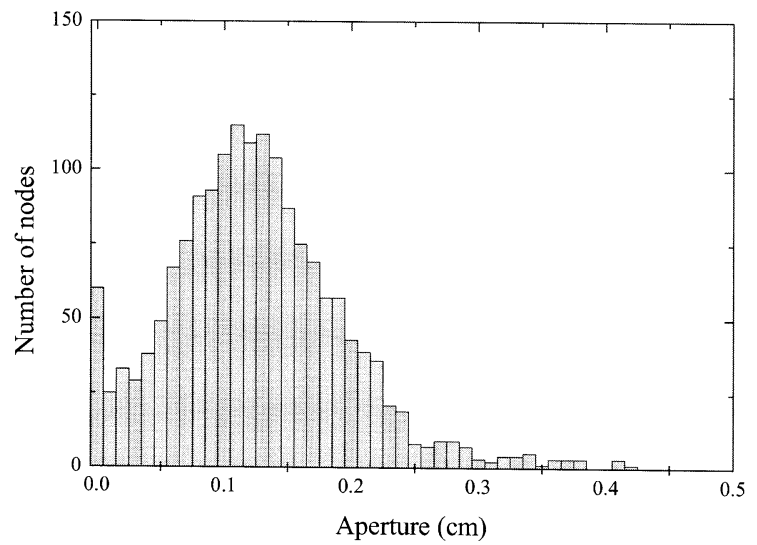

(b)

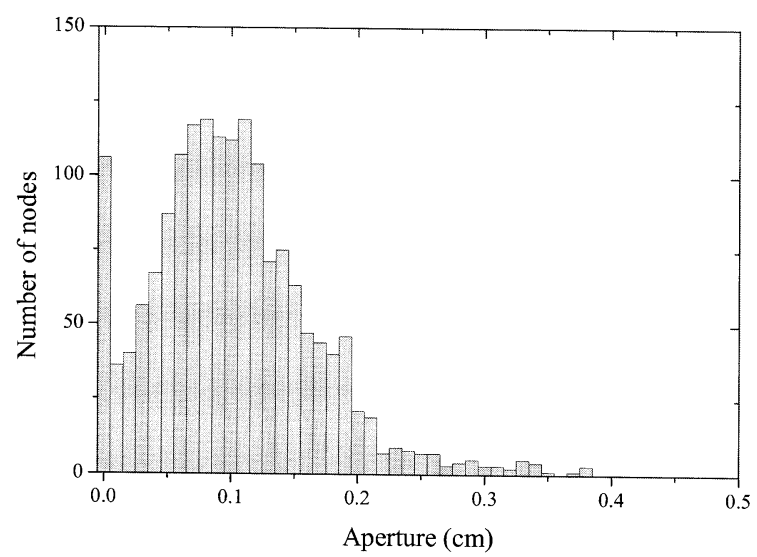

(c)

Fig. 4. Frequency histogram of aperture distributions under a normal stress: (a) without normal stress, (b) under the normal stress of 0.2 MPa and (c) under the normal stress of 2.0 MPa

obtained results have good correlations with the known aperture measurements (Yeo et al., 1998). That is, during the shear sliding, both the mean and the standard deviation of the aperture distribution are increased, such that the frequency distribution moves to the right and the width of the distribution is increased. On the contrary, under increasing normal stress, only the mean of the aperture is decreased and the standard deviation of the aperture remains constant, so that the frequency distribu- tion shifts to the left without changing the width of the distribution. This indicates the fact that the deformation is concentrated on the small contact area.

\section{Flow Simulation for a Single Joint}

Flow characteristic through a single rough rock joint with variable apertures has been effectively explained by solving the Reynolds equation numerically (Brown, 1987; Zimmerman and Bodvarsson, 1996). It has been found that when head gradient in a vertical direction against flow direction is assumed negligible, the Reynolds equation can be written as follows:

$$
\nabla\left(\frac{a(x, y)^{3}}{12 \mu} \nabla H(x, y)\right)=0
$$

where $a(x, y)$ and $H(x, y)$ indicate aperture and hydraulic head, respectively. $\mu$ is viscosity of fluid.

Only the aperture distribution is required in solving Eq. (1) by the finite element technique. In the present deformation-flow analysis, the previous deformation analysis is combined with the flow analysis using the Reynolds equation. Typical results of the deformationflow analysis are shown in Figs. 5 and 6 . The profile of the aperture surface is obtained in the form of a grid of $75 \times 75$ elements $(75 \mathrm{~mm} \times 75 \mathrm{~mm})$, cut out from a replica of a rock joint surface of $300 \mathrm{~mm} \times 300 \mathrm{~mm}$. Since the profiles of the rock joint were obtained in $0.5 \mathrm{~mm}$ pitch, minimum resolution of $0.5 \mathrm{~mm}$ in the shear displacement can be obtained.

In Fig. 5, it is shown that the flows through the single rough joint are considerably different in two perpendicular directions, although the same aperture distribution is used in solving Eq. (1). In Fig. 6, the transmissivities calculated at various normal stress and shear displacement conditions are indicated. In this study, the shear displacement level is raging only up to $2.0 \mathrm{~mm}$, in order to show the detailed flow characteristics of the joints located in a deep underground where the deformation may be restricted because of the high in-situ stresses. From the figures, it can be seen that at constant shear displacement, the transmissivity is decreased by the normal stress, but increases by the shear displacement at constant levels of normal stress.

\section{Analytical Approximation Solution for Flow through a Single Joint}

In general, the conditions of shear displacement and normal stress of joints around the excavation can significantly vary depending on the positions at which the joints are located. Although the combination of the 3-d finite element analysis using the 2-d joint elements and the finite element solution of the Reynolds equation can well simulate the flow characteristics of deforming joints, the execution of these numerical analysis to compute the joint transmissivities under those various conditions is quite time-consuming. Therefore, authors have recently solved the Reynolds equation analytically (Inoue and Sugita, 2003), and the characteristics of flow through a single joint has been investigated using the derived 




(a)

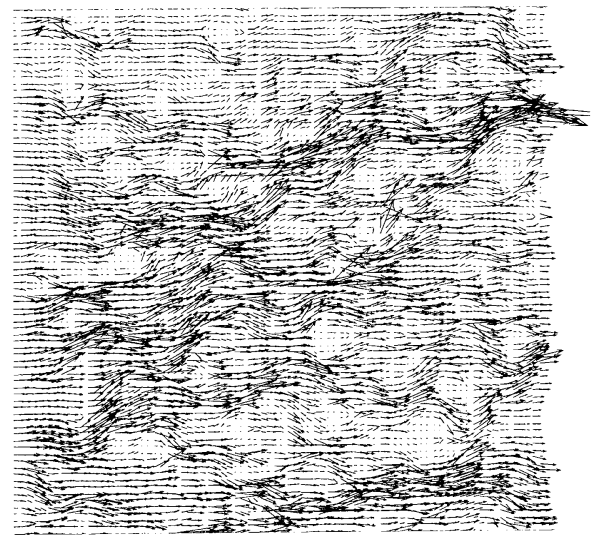

(b)

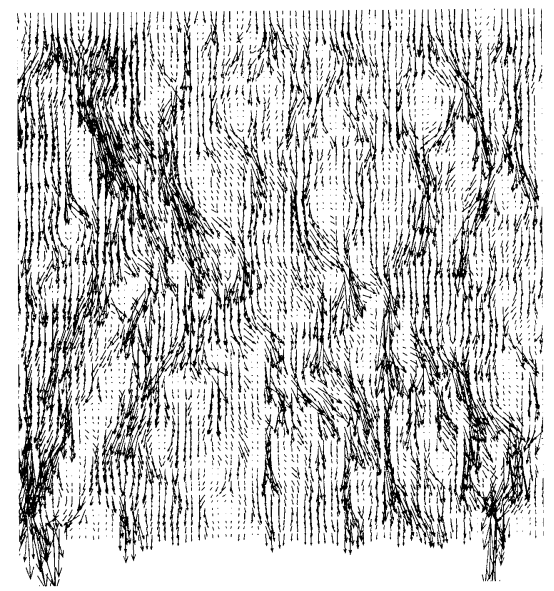

(c)

Fig. 5. Flow through a single rough rock joint simulated in the flow analysis; the calculated total flow rates in the simulation were 36.7 and $52.5 \mathrm{~mm}^{2} / \mathrm{s}$ for $x$ and $y$ directional flow, respectively; Note that the local flow vectors are considerably different in two directions, even if the same aperture distribution was used: (a) input aperture distribution, (b) $x$-directional flow and (c) $y$-directional flow

analytical approximation of effective transmissivity (Kim and Inoue, 2003). By applying perturbative expansion method (Beran, 1968) to Eq. (1), the analytical approximation solution for the effective transmissivity through a single joint with variable apertures can be obtained (see

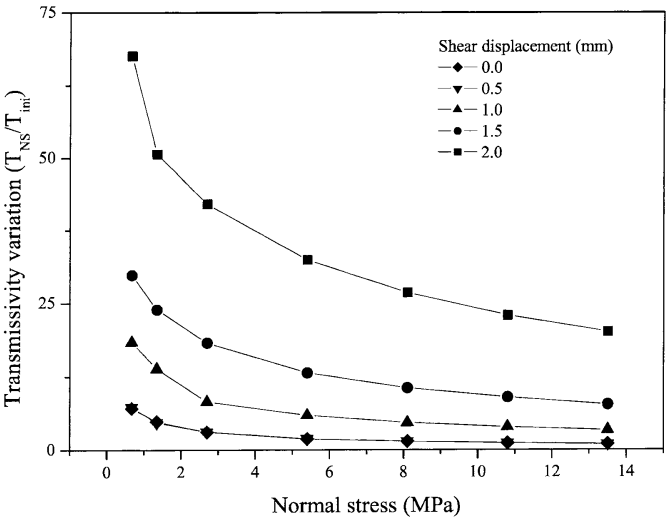

(a)

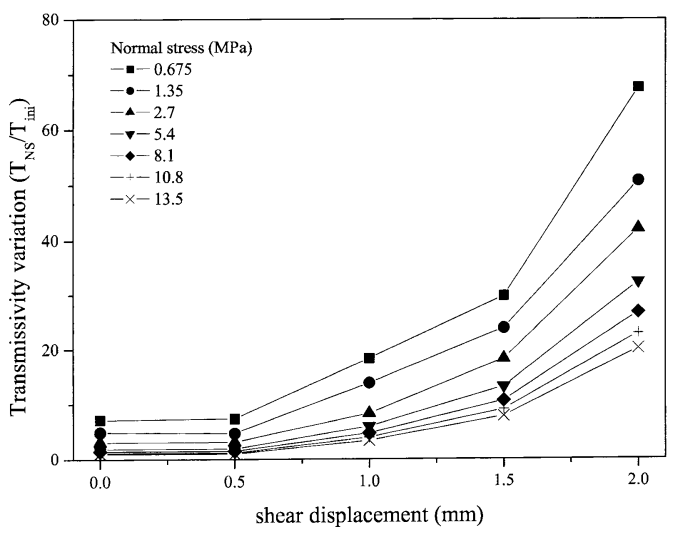

(b)

Fig. 6. A typical representation of the transmissivities of a joint under deformation; All the points in the figures were obtained from the combined deformation and flow analysis in a single joint at different shear displacement and normal stress conditions; Transmissivity in the vertical axis is a multiple proportion of transmissivity for zero shear displacement and normal stress of 13.5 MPa: (a) at constant normal stress and (b) at constant shear displacement

Inoue and Sugita (2003) for detailed derivation):

$$
\begin{aligned}
\bar{K}_{\mathrm{ij}}^{\mathrm{eff}}= & C \bar{A}^{3}\left[\left(1+3 \frac{\sigma_{\mathrm{A}}^{2}}{\bar{A}^{2}}\right) \delta_{\mathrm{ij}}-9 \alpha_{\mathrm{ij}} \frac{\sigma_{\mathrm{A}}^{2}}{\bar{A}^{2}}\right. \\
& \left.+9\left(\alpha_{\mathrm{ij}}-3 \alpha_{\mathrm{ij}}^{2}+9 \gamma_{\mathrm{ij}}\right) \frac{\sigma_{\mathrm{A}}^{4}}{\bar{A}^{4}}\right]
\end{aligned}
$$

where $C$ is the constant, determined by the water properties, $\bar{A}$ and $\sigma_{\mathrm{A}}$ indicate the mean and the standard deviation of an aperture distribution, $\alpha_{\mathrm{ij}}$ and $\gamma_{\mathrm{ij}}$ are the coefficients depending on the auto-correlation function of the aperture distribution, and $\delta_{\mathrm{ij}}$ is the Kronecker delta. The coefficients, $\alpha_{\mathrm{ij}}$ and $\gamma_{\mathrm{ij}}$, are defined as follows:

$$
\begin{aligned}
\alpha_{\mathrm{ij}}= & \int_{-\infty}^{\infty} \frac{d \mathbf{u}}{(2 \pi)^{2}} \hat{\rho}(\mathbf{u}) \frac{u_{\mathrm{i}} u_{\mathrm{j}}}{\mathbf{u}^{2}} \\
\gamma_{\mathrm{ij}}= & \int_{-\infty}^{\infty} \frac{d \mathbf{u} d \mathbf{v}}{(2 \pi)^{4}} \hat{\rho}(\mathbf{u}) \hat{\rho}(\mathbf{v})\left[\frac{\mathbf{u} \cdot u_{\mathrm{i}}\left(u_{\mathrm{j}}+v_{\mathrm{j}}\right)}{\mathbf{u}^{2}(\mathbf{u}+\mathbf{v})^{2}}\right. \\
& \left.+\frac{\mathbf{u} \cdot \mathbf{v} \mathbf{v} \cdot(\mathbf{u}+\mathbf{v}) u_{\mathrm{i}} u_{\mathrm{j}}}{\mathbf{u}^{2} \mathbf{v}^{2}(\mathbf{u}+\mathbf{v})^{2}}+\frac{\mathbf{u} \cdot \mathbf{v u} \cdot(\mathbf{u}+\mathbf{v}) u_{\mathrm{i}} v_{\mathrm{j}}}{\mathbf{u}^{4}(\mathbf{u}+\mathbf{v})^{2}}\right]
\end{aligned}
$$


where $\mathbf{u}$ and $\mathbf{v}$ are the position vectors in the wave space, and $\hat{\rho}$ is the Fourier transform of the auto-correlation function for the aperture distribution.

What is most distinguished in this analytical approach from the numerical techniques in predicting transmissivity of a single joint is that the second order statistical moment of spatial correlation for the aperture distribution as well as the first order moment of the aperture are included "explicitly". Thus, under various conditions of shear displacements and normal stresses to be considered, the overall transmissivity of a single rough joint can be effectively evaluated, once the information about the statistical parameters of the apertures are obtained. Of course, with the present analytical approach, it is impossible to discuss such a microscopic behavior as the effect of each asperities.

The variation of these statistical parameters under a normal and a shear deformation has been well introduced and applied to the investigation of the flow through joints with rough surfaces (Mourzenko et al., 1997; Kim and Inoue, 2003). In these studies, the statistical parameters of an aperture distribution are derived from those of a joint surface roughness, so that the information of the joint surface asperities is sufficient enough to examine the joint transmissivity of the deforming joints. The relations between the statistical parameters of a surface asperity and the aperture distribution are shown as below for a shear deformation:

$$
\begin{aligned}
\operatorname{Cov}_{\mathrm{A}}(x, y)= & 2 \operatorname{Cov}_{\mathrm{Z}}(x, y)-\operatorname{Cov}_{\mathrm{Z}}\left(x-d_{\mathrm{x}}, y-d_{\mathrm{y}}\right) \\
& -\operatorname{Cov}_{\mathrm{Z}}\left(x+d_{\mathrm{x}}, y+d_{\mathrm{y}}\right) \\
\sigma_{\mathrm{A}}^{2}=\operatorname{Cov}_{\mathrm{A}}(0,0)= & 2 \sigma_{\mathrm{Z}}^{2}-\operatorname{Cov}_{\mathrm{Z}}\left(d_{\mathrm{x}}, d_{\mathrm{y}}\right)-\operatorname{Cov}_{\mathrm{Z}}\left(d_{\mathrm{x}}, d_{\mathrm{y}}\right)
\end{aligned}
$$

where $\operatorname{Cov}$ and $\sigma$ indicate the covariance function and the standard deviation, and subscript $Z$ and $A$ indicate surface asperities and aperture distribution, respectively. $d_{\mathrm{i}}(i=x, y)$ is the shear dislocation between upper and lower surfaces.

When a normal stress is applied, a joint will close because of the deformation at the contacted area of upper and lower surfaces. Judging from the aforementioned results of the numerical study, the change in the standard deviation of an aperture distribution is almost negligible, hence the deformation is considered to concentrate only on the very small contacted surface asperities. By assuming that the contact surface is significantly small as compared with the total surface area, the parameters of the aperture distribution of the joints under a normal deformation can be analytically estimated (Mourzenko et al., 1997). The relation between the normal closure $V$ and the stress $\sigma_{\mathrm{n}}$ is written as follow:

$$
V=4 \frac{\left(1-v^{2}\right)}{E} \frac{\left(1-S_{\mathrm{c}}\right)}{S_{\mathrm{c}}} L_{\mathrm{c}} \sigma_{\mathrm{n}}
$$

where $E$ and $v$ are the Young's modulus and the poisson ratio for the intact rock, while $S_{\mathrm{c}}$ is the area of contact dependent on the standard deviation of the surface roughness and the normal stress $\sigma_{\mathrm{n}}$ :

$$
S_{\mathrm{c}}=\frac{1}{2}\left[1-\operatorname{erf}\left(\frac{\bar{A}}{2 \sigma_{\mathrm{A}}}\right)\right]
$$

and $L_{\mathrm{c}}$ indicates the characteristic correlation length determined by the correlation function (see Mourzenko et al. (1997) for detailed derivation):

$$
L_{\mathrm{c}}=\frac{1}{2 \pi S_{\mathrm{c}}\left(1-S_{\mathrm{c}}\right)} \int_{0}^{1} \sigma_{\mathrm{A}}^{2} \operatorname{Cov}_{\mathrm{A}}^{-1}(\gamma) \frac{\exp \left[-\bar{A}^{2} / 2 \sigma_{\mathrm{A}}^{2}(1+\gamma)\right]}{\sqrt{1-\gamma^{2}}} d \gamma
$$

The average aperture $\bar{A}$ is obtained numerically for each level of the normal stress $\sigma_{\mathrm{n}}$, by finding the solution satisfying Eqs. (7)-(9). The initial average aperture $\bar{A}_{0}$ is assumed to be $5 \sigma_{\mathrm{A}}$ in the numerical derivation of the solution, after Mourzenko et al. (1997).

\section{Validation of Analytical Approximation Solution with Numerical Simulations}

In this study, in order to obtain statistically sufficient number of numerical results, the aperture distribution is generated randomly, instead of using replica of rock joint surfaces. The surfaces are generated using the Fourier transform technique (Adler and Thovert, 1999), and the Gaussian correlation function is introduced, for simplicity. If we know the correlation function for a specific site, we should use that function instead, though. The Gaussian correlation function in two dimensions is defined as below:

$$
\text { Cor }_{\text {Gaussian }}=\operatorname{Exp}\left[-\left(\frac{x}{\lambda_{\mathrm{x}}}\right)^{2}-\left(\frac{y}{\lambda_{\mathrm{y}}}\right)^{2}\right]
$$

where $\lambda_{\mathrm{i}}$ is the characteristic correlation length at each direction of $x$ and $y$. In the present paper, only the isotropic case $\left(\lambda_{x}=\lambda_{y}=\lambda\right)$ is demonstrated.

Figure 7 compares the flow rate through a single joint under shear deformation by the analytical approximation solution and by the numerical estimation using randomly generated surfaces.

The numerical results in Fig. 7 are obtained using a grid of $100 \times 100$ quadrilateral elements, which are extracted from the initially generated grid of $2^{8} \times 2^{8}$ elements. In Fig. 7(a), it is noted that the increment of the standard deviation for the aperture distribution rises remarkably with increasing shear displacement, but stabilizes at the shear displacement equivalent to two times the correlation length of the surface roughness. The mean aperture, which controls flow rate, is calculated by Eqs. (7)-(9) using this standard deviation, since the ratio between the mean aperture and the standard deviation of aperture has not significantly changed during the shear deformation under the constant normal stress as shown in the result of the numerical study (Kim and Inoue, 2003).

Figure 7(b) demonstrates the permeability derived using Eq. (2). It can be seen that both numerical and analytical results are in good accordance in that the flow perpendicular to shear direction is more dominant rather than parallel direction during the shear sliding. The difference in transmissivities between two directions can 


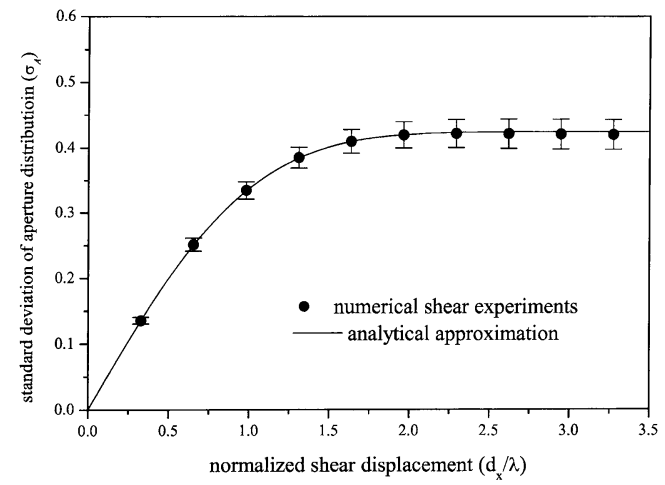

(a)

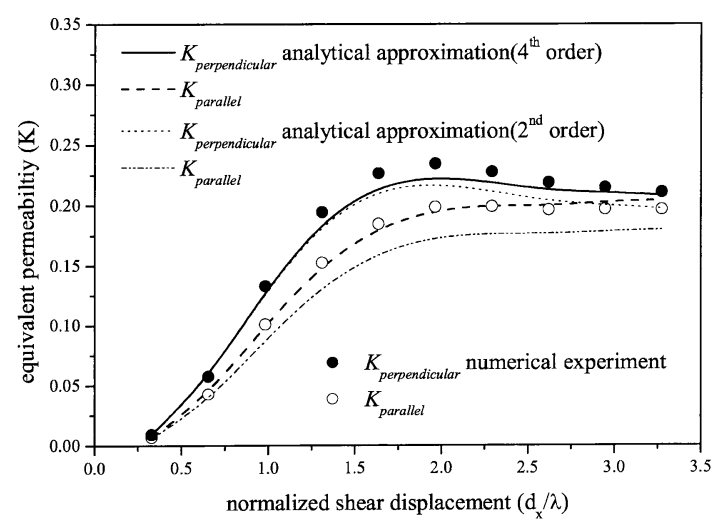

(b)

Fig. 7. Typical results of the analytical methods for the flow properties through a single rough joint under a shear deformation; Shear displacement in the figure is normalized by the characteristic correlation length of joint surface; The dotted line indicates the results by the numerical analysis, and the curves are obtained from Eq. (2); Note that the numerical and analytical results are in good agreement: (a) standard deviation of aperture distribution and (b) average permeability

be defined as anisotropy, which changes depending on the shear displacement. Furthermore, the decreasing incremental rate of the flow rate with increasing shear displacement, as shown in the shear flow experiments (Esaki et al., 1999), can be observed in Fig. 7. From the Fig. 7(b), it can also be noted that the permeability perpendicular to the shear direction $K_{\text {perpendicular }}$ has its peak at around $2 \lambda$. This is because the structure in the aperture distribution, which creates flow channel in the direction perpendicular to the shear direction, will gradually vanish as the shear deformation exceed $2 \lambda$ due to the loss of correlation between the upper and lower surfaces, although the average aperture stays almost constant.

\section{EXCAVATION INDUCED DISTURBANCE IN A JOINTED ROCK MASS}

Excavation induced transmissivities of individual joints in rock mass depend on the shear displacement and the normal stress caused by the excavation induced stress

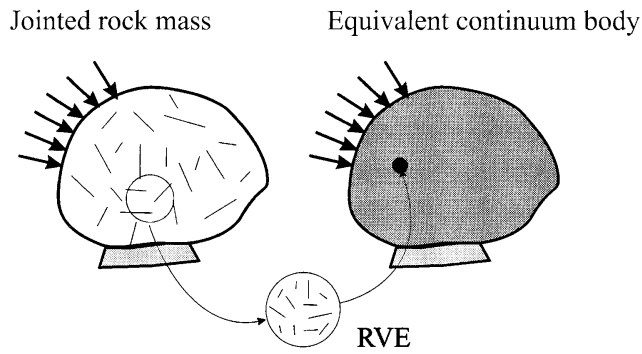

Fig. 8. Representative volume element (RVE)

redistribution. In the present study, the Micromechanics Based Continuum (MBC) model analysis is adopted in order to obtain the excavation induced shear displacement and normal stress on the pre-existing joints around the opening.

Fundamental foundation of the MBC model is the constitutive relation between the average stress and the average strain over the Representative Volume Element (RVE), which is shown in Fig. 8.

The average stress and the average strain over the RVE are given as follows, together with the incremental form of the constitutive relationship of a body containing discontinuity (Horii and Nemat-Nasser, 1983).

$$
\begin{aligned}
& \overline{\sigma_{\mathrm{ij}}}=\frac{1}{V} \int_{V} \sigma_{\mathrm{ij}} d V \\
& \overline{\varepsilon_{\mathrm{ij}}}=\frac{1}{2 V} \int_{\delta V}\left(u_{\mathrm{i}} n_{\mathrm{j}}+u_{\mathrm{j}} n_{\mathrm{i}}\right) d S \\
& \Delta \overline{\varepsilon_{\mathrm{ij}}}=D_{\mathrm{ijkl}}^{\mathrm{R}} \Delta \overline{\sigma_{\mathrm{kl}}}+\frac{1}{2 V} \sum_{\alpha} \int_{\Omega^{\alpha}}\left(\Delta\left[u_{\mathrm{i}}\right] n_{\mathrm{j}}+\Delta\left[u_{\mathrm{j}}\right] n_{\mathrm{i}}\right) d S
\end{aligned}
$$

where $V$ and $\delta V$ are the volume and the exterior surface of the RVE, $\mathbf{u}$ indicates the displacement vector, and $\mathbf{n}$ shows the unit vector normal to $\delta V . D_{\mathrm{ijkl}}^{\mathrm{R}}$ is an elastic compliance tensor, $\Omega^{\alpha}$ is the surface of the $\alpha^{\text {th }}$ joint. The incremental displacement jump across the joint is denoted by $\Delta\left[u_{\mathrm{i}}\right]=\left(u_{\mathrm{i}}^{+}-u_{\mathrm{i}}^{-}\right)$.

Overall constitutive equation is obtained when $\Delta\left[u_{\mathrm{i}}\right]$ is expressed as a function of the incremental average stress $\Delta \bar{\sigma}_{\mathrm{ij}}$ in Eq. (13). This is possible when a single joint is embedded in a homogeneous material. In the $\mathrm{MBC}$ model analysis, the problem is first decomposed into (1) homogeneous intact rock, (2) rock with traction acting on an open joint, and (3) cut-out joint problem (Horii and Yoshida, 1994). By the decomposition, constraint on the joint deformation by the surrounding rock mass is expressed simply in terms of system stiffness (Cai and Horii, 1992), in which the reduction of overall stiffness due to the existence of joints is considered in self-consistent manner. The overall constitutive relationship of the jointed rock masses can then be written as the summation of the average strains over all existing joint sets, and the elastic strain of the intact rock, as follows:

$$
\Delta \bar{\epsilon}_{\mathrm{ij}}=\left(D_{\mathrm{ijkl}}^{\mathrm{R}}+\sum_{\mathrm{m}} D_{\mathrm{ijkl}}^{(\mathrm{m})}\left(\bar{E}^{(\mathrm{m})}, \bar{G}^{(\mathrm{m})}\right)\right) \Delta \overline{\sigma_{\mathrm{kl}}}
$$




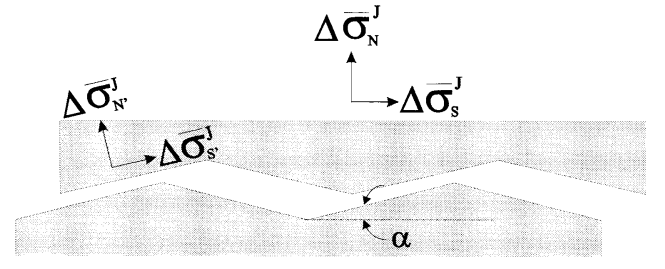

Fig. 9. Sawtooth undulation of cut-out joints with the undulation angle $\alpha$

where $D_{\mathrm{ijkl}}^{\mathrm{R}}$ is the elastic compliance of the intact rock, and $D_{\mathrm{ijkl}}^{(\mathrm{m})}$ is the compliance due to the $m^{\text {th }}$ embedded discontinuity.

In the summed terms in Eq. (14), the effective moduli for the normal and shear deformation of the $m^{\text {th }}$ joint, $\bar{E}^{(\mathrm{m})}$ and $\bar{G}^{(\mathrm{m})}$, are used. Those moduli are different and decreased from the stiffness of an intact rock due to the existence of the other joints. Theoretically, those parameters can be determined by directly solving Eq. (14), assuming that the effective moduli are equal to the overall moduli. In the MBC analysis, however, an iterative procedure is applied to determine those parameters for simplicity as proposed by Cai and Horii (1992), in the following way. First, joints are assumed to be embedded in an intact rock, and the tangential effective Young's modulus $\bar{E}^{(\mathrm{m})}$ in the direction normal to the joint and the tangential effective shear modulus $\bar{G}^{(\mathrm{m})}$ in Eq. (14) are replaced with the Young's modulus $E$ and the shear modulus $G$ of the intact rock, and the overall tangential compliance is calculated as

$$
\tilde{D}_{\mathrm{ijkl}}=D_{\mathrm{ijkl}}^{\mathrm{R}}+\Sigma_{\mathrm{m}} D_{\mathrm{ijkl}}^{(\mathrm{m})}(E, G)
$$

Then, the tangential effective moduli, $\bar{E}^{(\mathrm{m})}$ and $\bar{G}^{(\mathrm{m})}$, for each joints are determined assuming that the $m^{\text {th }}$ joint is included in the material with the computed compliance $\tilde{D}_{\mathrm{ijk} 1}$. The final constitutive equation for the rock masses with those joints is obtained as

$$
\Delta \bar{\epsilon}_{\mathrm{ij}}=\left(D_{\mathrm{ijkl}}^{\mathrm{R}}+\Sigma_{\mathrm{m}} D_{\mathrm{ijkl}}^{(\mathrm{m})}\left(\tilde{E}^{(\mathrm{m})}, \tilde{G}^{(\mathrm{m})}\right)\right) \Delta \overline{\sigma_{\mathrm{kl}}}
$$

which can be simply rewritten as

$$
\Delta \overline{\epsilon_{\mathrm{ij}}}=\bar{D}_{\mathrm{ijkl}} \Delta \overline{\sigma_{\mathrm{k} 1}}
$$

where $\bar{D}_{\mathrm{ijk} 1}$ is the tangential compliance tensor of the equivalent continuum.

The representative characteristics of the MBC model analysis is to provide shear and opening displacement of embedded joints, which are explained by sliding between two sawtooth undulated surfaces (Fig. 9). From the assumption of the sawtooth undulated surface, the explicit form of $D_{\mathrm{ijkl}}^{(\mathrm{m})}$ is given by combining following equations:

Consistency condition:

$$
\left|\Delta \bar{\sigma}_{\mathrm{s}}^{\mathrm{J}^{\prime}}\right|=-\Delta \bar{\sigma}_{\mathrm{n}}^{\mathrm{J}^{\prime}} \tan \phi
$$

where $\Delta \bar{\sigma}_{\mathrm{n}}^{\mathrm{J}^{\prime}}$ and $\Delta \bar{\sigma}_{\mathrm{s}}^{\mathrm{J}^{\prime}}$ are the incremental average tractions acting on the inclined sliding surface, and $\phi$ is the frictional angle of the local surface of the joint.

Equilibrium condition:

$$
\begin{aligned}
& \Delta \bar{\sigma}_{\mathrm{n}}^{\mathrm{J}}=\frac{1}{2}\left(\Delta \bar{\sigma}_{\mathrm{s}}^{\mathrm{J}^{\prime}} \tan \alpha+\Delta \bar{\sigma}_{\mathrm{n}}^{\mathrm{J}^{\prime}}\right), \\
& \Delta \bar{\sigma}_{\mathrm{s}}^{\mathrm{J}}=\frac{1}{2}\left(\Delta \bar{\sigma}_{\mathrm{s}}^{\mathrm{J}^{\prime}}-\Delta \bar{\sigma}_{\mathrm{n}}^{\mathrm{J}^{\prime}} \tan \alpha\right)
\end{aligned}
$$

where $\Delta \bar{\sigma}_{\mathrm{n}}^{\mathrm{J}}$ and $\Delta \bar{\sigma}_{\mathrm{n}}^{\mathrm{J}}$ are the incremental average tractions acting on the joint, while $\alpha$ is the undulation.

Coordinate transformation:

$$
\begin{aligned}
& \Delta\left[\bar{u}_{\mathrm{n}}^{\mathrm{J}}\right]=\Delta\left[\bar{u}_{\mathrm{s}}^{\mathrm{J}}\right] \sin \alpha \\
& \Delta\left[\bar{u}_{\mathrm{s}}^{\mathrm{J}}\right]=\Delta\left[\bar{u}_{\mathrm{s}}^{\mathrm{J}^{\prime}}\right] \cos \alpha \\
& \Delta\left[\bar{u}_{\mathrm{n}}^{\mathrm{J}}\right]=0
\end{aligned}
$$

$\Delta\left[\bar{u}^{\mathrm{J}}\right]$ is the incremental average displacement jump with respect to the joint plane and $\Delta\left[\bar{u}^{\mathrm{J}^{\prime}}\right]$ is with respect to the sliding sub-surface.

Solutions for single crack problem in infinite domain:

$$
\begin{aligned}
& \Delta \bar{\sigma}_{\mathrm{n}}-\Delta \bar{\sigma}_{\mathrm{n}}^{\mathrm{J}}=\bar{K}_{\mathrm{n}} \Delta\left[\bar{u}_{\mathrm{n}}^{\mathrm{J}}\right] \\
& \Delta \bar{\sigma}_{\mathrm{s}}-\Delta \bar{\sigma}_{\mathrm{s}}^{\mathrm{J}}=\bar{K}_{\mathrm{s}} \Delta\left[\bar{u}_{\mathrm{s}}^{\mathrm{J}}\right]
\end{aligned}
$$

where $\bar{K}_{\mathrm{n}}$ and $\bar{K}_{\mathrm{s}}$ are the normal and the shear stiffness of the system defined as

$$
\begin{aligned}
& \bar{K}_{\mathrm{n}}=\frac{2 \bar{E}}{\lambda_{\mathrm{n}}^{0} \bar{L}^{\mathrm{j}}} \\
& \bar{K}_{\mathrm{s}}=\frac{2 \bar{G}}{\lambda_{\mathrm{s}}^{0} \bar{L}^{\mathrm{J}}} .
\end{aligned}
$$

where $\lambda_{\mathrm{n}}^{0}$ and $\lambda_{\mathrm{s}}^{0}$ are explicitly given for a penny-shaped joint as $\lambda_{\mathrm{n}}^{0}=16\left(1-v^{2}\right) / 3 \pi$ and $\lambda_{\mathrm{s}}^{0}=16(1-v) / 3 \pi(2-v)$. $\bar{L}^{\mathrm{J}}$ is the effective joint length, which includes the effect of the joint intersection, hence is dependent on the joint densities and the joint orientations.

With this concept, the model can explain the opening displacement of the joints, which is even under compressive stress conditions due to the excavation (see Yoshida and Horii (2004) for more detail on the derivation of $D_{\mathrm{ijkl}}^{(\mathrm{m})}$ ).

\section{FLOW ANALYSIS IN EXCAVATION DISTURBED ZONE (EDZ)}

\section{Discrete Network Model Analysis}

In the present study, a flow simulation in a jointed rock mass is conducted by using the discrete joint network model. The network consists of 2-dimensional plane joints with multiple edges, which are randomly and independently distributed in the 3-dimensional space. By this discrete network model, a flow in a jointed rock mass can be simply represented as the flow through the network.

For an incompressible flow in the 2-d joints in the network, flow equation is usually written as follows:

$$
S \frac{\partial h}{\partial t}-\nabla(\mathbf{T} \nabla h)=q
$$

where $S$ and $\mathbf{T}$ indicate storativity (dimensionless) and transmissivity $\left(\mathrm{m}^{2} / \mathrm{s}\right)$, respectively. $h$ is hydraulic head (m), and $q$ is source or sink term, which indicates the 
Table 1. Parameters assigned for the MBC model analysis

\begin{tabular}{|c|c|c|c|c|}
\hline \multirow{2}{*}{ Parameters } & \multicolumn{2}{|c|}{ Case\#1 } & \multicolumn{2}{|c|}{ Case $\# 2$} \\
\hline & Set\#1 & Set\#2 & Set\#1 & Set\#2 \\
\hline Dip angle $\left({ }^{\circ}\right)$ & 45 & 135 & 80 & 110 \\
\hline Effective length (m) & 1.25 & 1.25 & 1.05 & 1.05 \\
\hline Average spacing $(\mathrm{m})$ & 1.0 & 1.0 & 1.0 & 1.0 \\
\hline Friction angle $\left({ }^{\circ}\right)$ & 30 & 30 & 35 & 35 \\
\hline Undulation $\left(^{\circ}\right)$ & 15 & 15 & 10 & 10 \\
\hline In-situ stress (MPa) & \multicolumn{2}{|c|}{$\begin{array}{c}18.9 \text { (vertical) } \\
0.3 \times \text { vertical } \\
\text { (horizontal) }\end{array}$} & \multicolumn{2}{|c|}{$\begin{array}{c}18.9 \text { (vertical) } \\
1.2 \times \text { vertical } \\
\text { (horizontal) }\end{array}$} \\
\hline
\end{tabular}

Table 2. Parameters used for the generation of discrete joints

\begin{tabular}{|c|c|c|}
\hline Parameters & Distribution & Values \\
\hline $\begin{array}{l}\text { Joint orientation } \\
\text { (strike/dip angle) }\end{array}$ & $\begin{array}{l}\text { Fisher } \\
\qquad(k=10)\end{array}$ & $\begin{array}{l}90 / 45 \text { and } 90 / 135 \text { (case } \# 1 \text { ) } \\
0 / 80 \text { and } 0 / 110 \text { (case } \# 2 \text { ) }\end{array}$ \\
\hline Joint shape & Uniform & Hexagonal \\
\hline Joint size $(\mathrm{m})$ & Lognormal & 1.25 and 1.25 \\
\hline Joint density $\left(\mathrm{m}^{2} / \mathrm{m}^{3}\right)$ & Uniform & 1.0 \\
\hline $\begin{array}{l}\text { Joint transmissivity } \\
\left(\mathrm{m}^{2} / \mathrm{s}\right)\end{array}$ & Lognormal & $1.0 \times 10^{-11}$ and $1.0 \times 10^{-10}$ \\
\hline
\end{tabular}

volume per unit area $(\mathrm{m} / \mathrm{s}) . t$ is time $(\mathrm{sec})$. Since in this study only a steady state problem is considered, the first term on the left side disappears.

In generating discrete joints, joint centers are usually considered to follow the Poisson distribution and are spatially distributed with the density that is defined as the total joint area per model volume $\left(\mathrm{m}^{2} / \mathrm{m}^{3}\right)$. Joint orientation, size, and transmissivity can also have different distributions as necessary.

\section{Description of Method}

The method for evaluating an excavation-induced change in the flow properties of a jointed rock mass is proposed by combining two different finite element programs, the MBC model analysis and the flow analysis using the discrete network model analysis. An entire analysis in the proposed approach is performed in the following sequence:

(1) Estimation of the shear displacement and the normal stress on joints induced by an excavation.

(2) Generation of a discrete network of joints.

(3) Transmissivity correction into the excavation induced transmissivity at all the elements on the individual joints.

(4) Evaluation of the change in the flow properties of jointed rock mass around the tunnel excavation.

The average shear displacement and the average normal stress induced by an excavation are estimated by the MBC model analysis, while the evaluation of the change in the flow properties of jointed rock mass is done by the discrete network model analysis.

Since the MBC model analysis is constructed by finding an equivalent continuum problem for the discrete joint problem, the results are given in the form of continuous functions of the average shear displacement and the

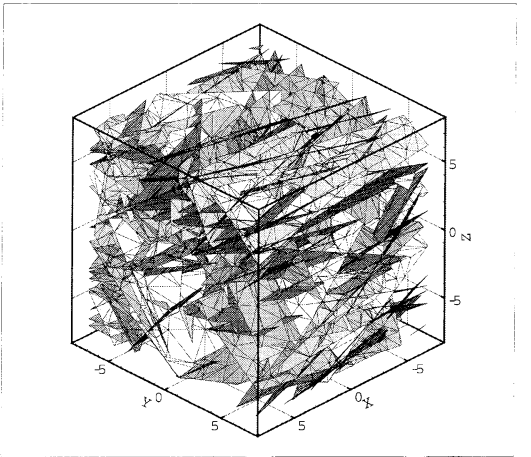

(a)

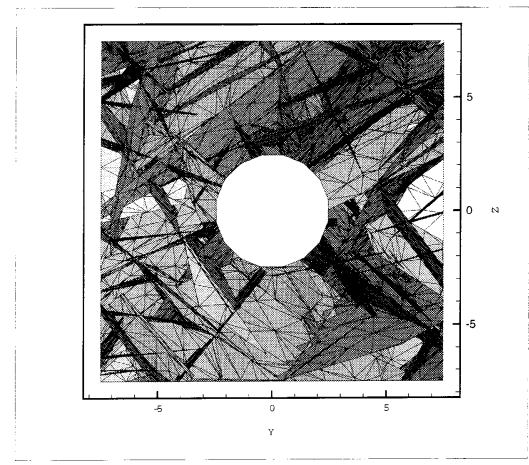

(b)

Fig. 10. An example of a discrete network of joints: (a) perspective plot and (b) front view

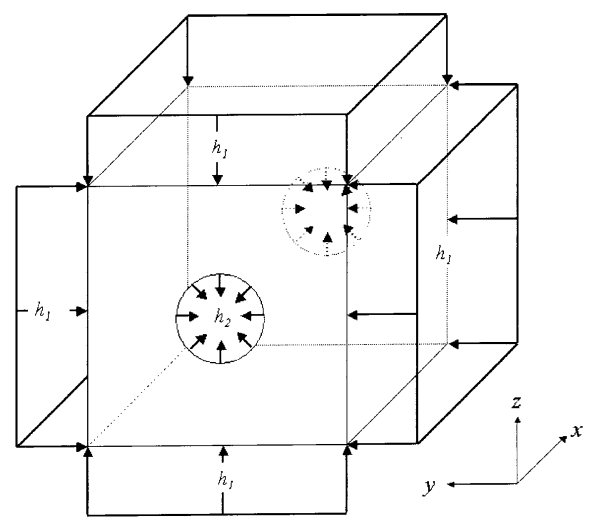

(a)

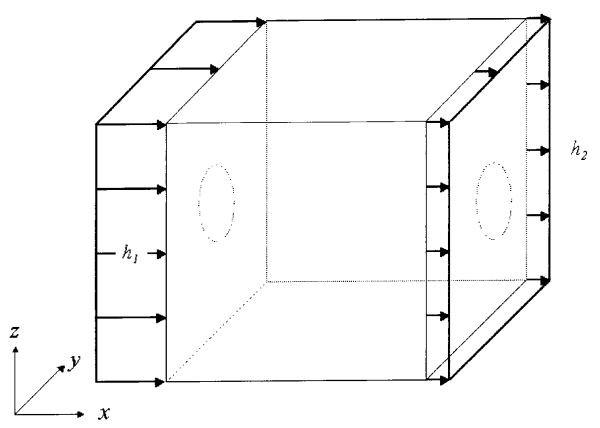

(b)

Fig. 11. Boundary conditions for flow analysis; Flow is triggered by the hydraulic head gradient between $h_{1}$ and $h_{2}\left(h_{1}>h_{2}\right)$ : (a) radial flow and (b) axial flow 


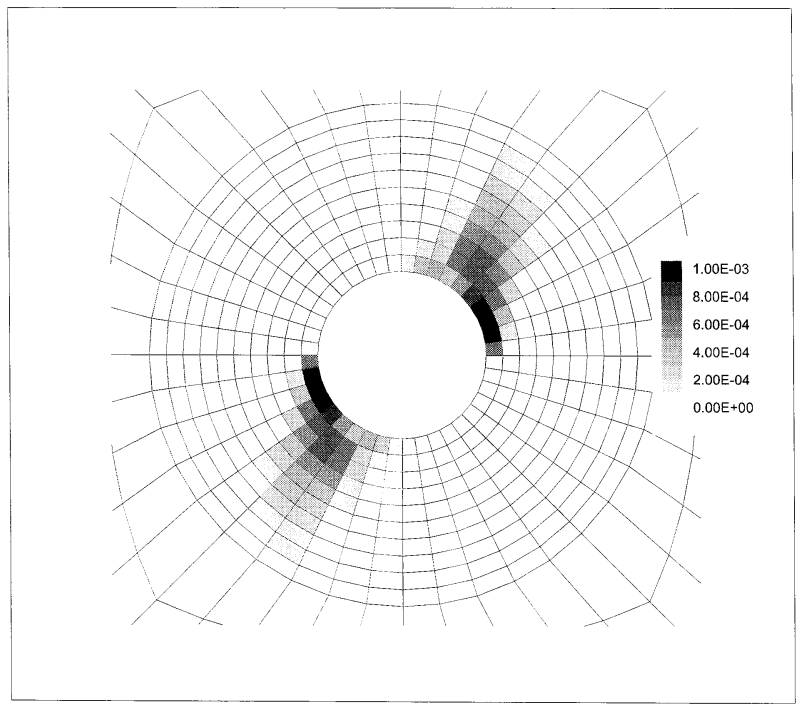

(a)



(c)



(b)

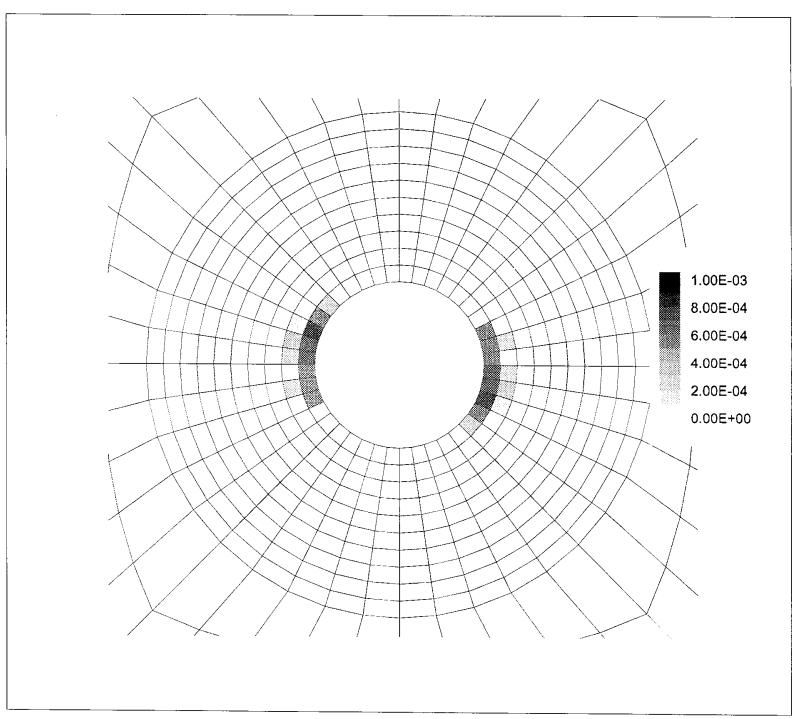

(d)

Fig. 12. Shear displacement distribution around the excavation of each set under the conditions shown in Table 1: (a) set\#1, case $\#$ (top, left), (b) set $\# 2$, case $\# 1$ (top, right), (c) set $\# 1$, case $\# 2$ (bottom, left) and (d) set $\# 2$, case $\# 2$ (bottom, right)

normal stress on joints. Consequently, the transmissivity of joints are estimated using the interpolated values of the average shear displacement and the normal stress obtained by the MBC model analysis.

The alteration of transmissivity is executed at each integral point of the elements in the flow analysis using the method described in FLOW IN A SINGLE ROUGH ROCK JOINT. In the present study, there is no real information about the joint surface, the Gaussian correlation function is adopted for demonstration purpose. Although the same transmissivities are initially assigned to all the elements on the same joint, excavation induced transmissivities at each element become different depending on the positions where the element is located, since the shear displacement or the normal stress at each place are not identical. The altered joint transmissivity is represented as a second order matrix in Eq. (28). Two principal directions in defining the joint transmissivity matrix at a local coordinate system are assumed to be parallel and perpendicular to the shear sliding direction.

\section{Parameter Correlations between Different Methods}

Since the parameters used in the MBC model analysis and those used in the other analysis are different, the parameters have to be transformed.

The undulation angle $\alpha$ for the assumed sawtooth surface in the MBC model analysis is determined as a slope angle formed by the shear displacement and consequent increment in the mean aperture during shear sliding of a single joint. The standard deviation of aperture distribution is calculated from that of the surface roughness (Eq. (6)), and the mean aperture is a multiple proportion of the standard deviation. In the present study, since the Gaussian correlation function is used for demonstration 


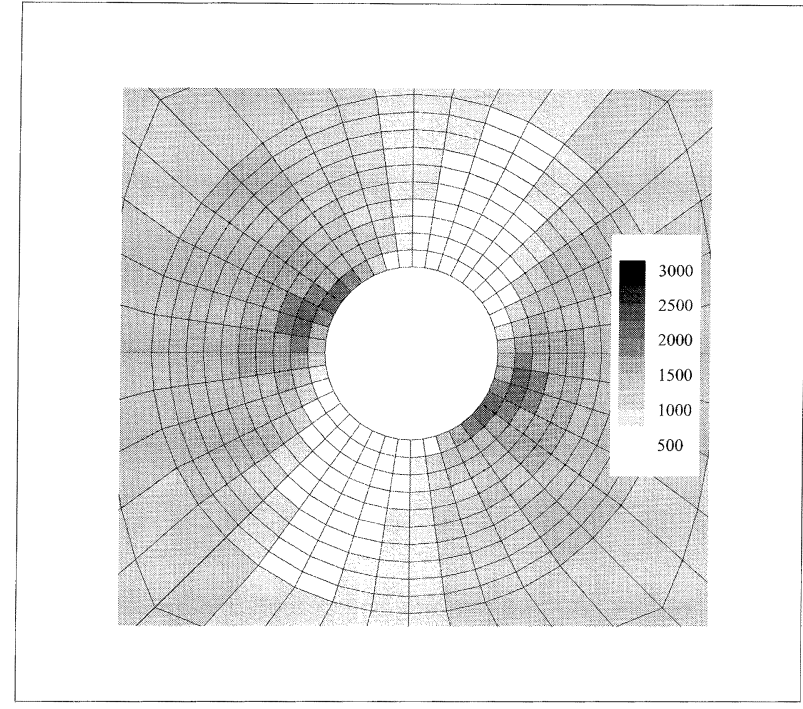

(a)

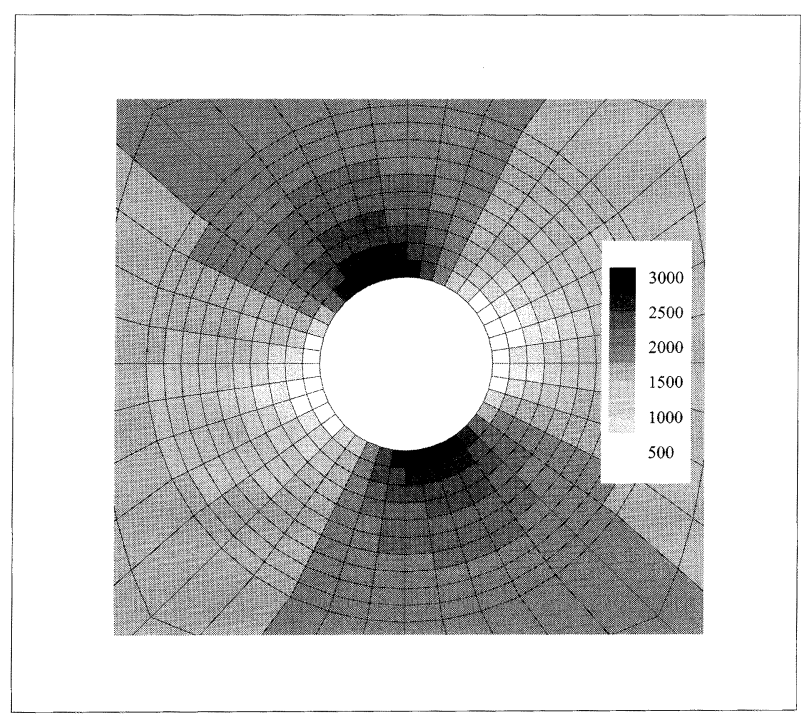

(c)

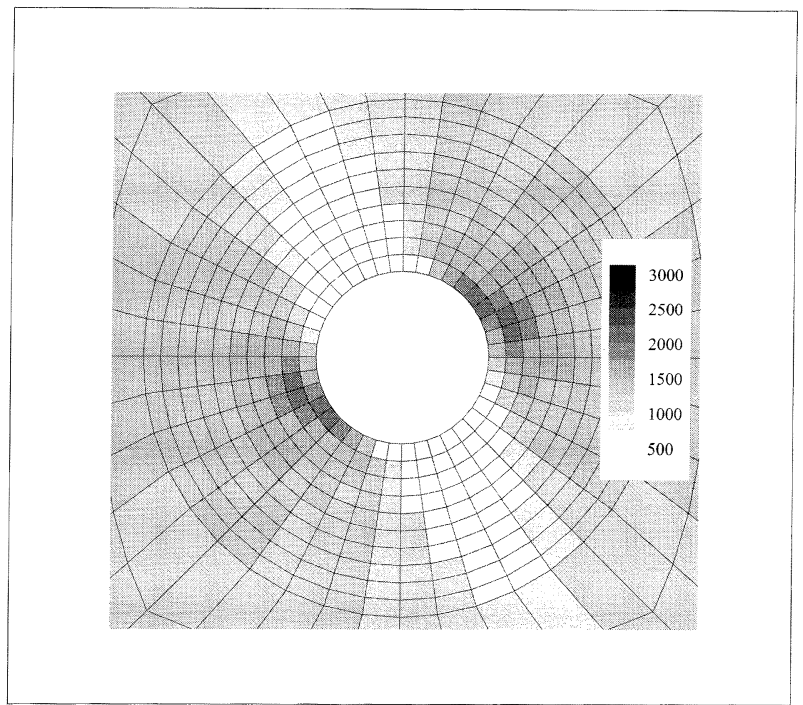

(b)

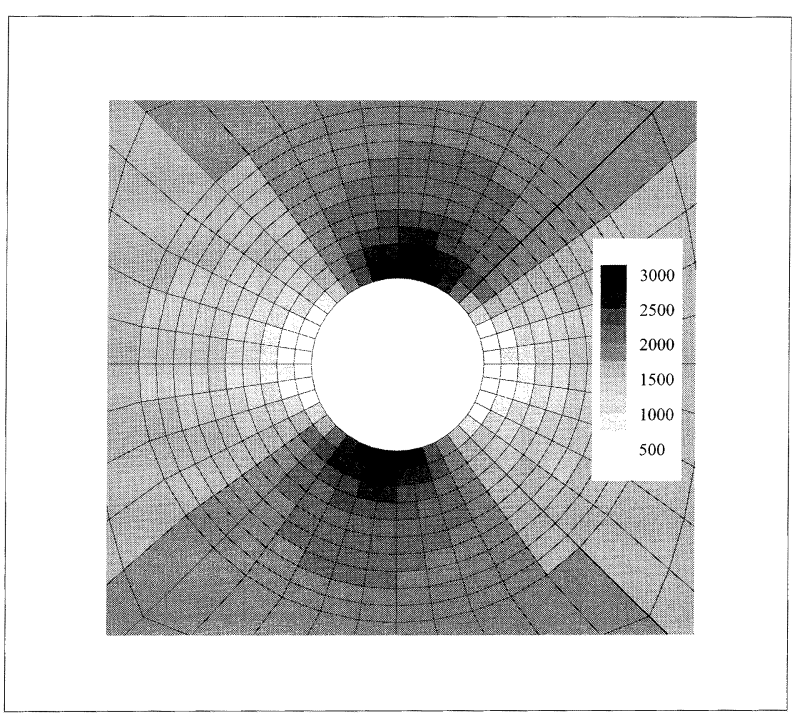

(d)

Fig. 13. Normal stress distribution around the excavation of each set under the conditions shown in Table 1: (top, left) set \#1, case\#1, (top, right) set $\# 2$, case $\# 1$, (bottom, left) set $\# 1$, case $\# 2$ and (bottom, right) set $\# 2$, case $\# 2$

purpose, the maximum mean aperture $\left(\bar{A}_{\max }\right)$ produced at the shear displacement which is almost equivalent to two times of the correlation length of surface asperity distribution (Fig. 7(a)) can be written as follows:

$$
\bar{A}_{\max }=C \sqrt{2} \sigma_{\mathrm{Z}}
$$

where $\sigma_{\mathrm{Z}}$ indicates the standard deviation of the surface roughness. $C$ is a constant that depends on the contact ratio of the surface, and defines the ratio between mean and standard deviation of the aperture distribution. It is known that the proportional constant $(C)$ has not changed significantly under shear deformation (Kim and Inoue, 2003), and if it is assumed, for simplicity, not to be changed under normal deformation as well, then the turning point, at which the mean aperture reaches its maximum and keeps almost constant even with further shear displacement in Fig. 7(a), may correspond to the pointed peak in the sawtooth shape in Fig. 9. From this, the undulation angle $\alpha$ for use in the MBC model analysis is computed as Eq. (30):

$$
\tan (\alpha)=\frac{\bar{A}_{\max }}{2 \lambda}
$$

where $\lambda$ is the characteristic correlation length of surface roughness defined in Eq. (10).

As mentioned above, in general, a joint is not isolated but intersects with other joints. Consequently, the constraint of the surrounding rock mass is weakened by such an effect. The effective length of joint set used in the MBC model analysis includes such an effect so as to have different value from the real joint length. Usually, the effective length of joint set is determined through the in-situ experimental result. Hence, the direct correlation between the effective length of joint in the MBC model 


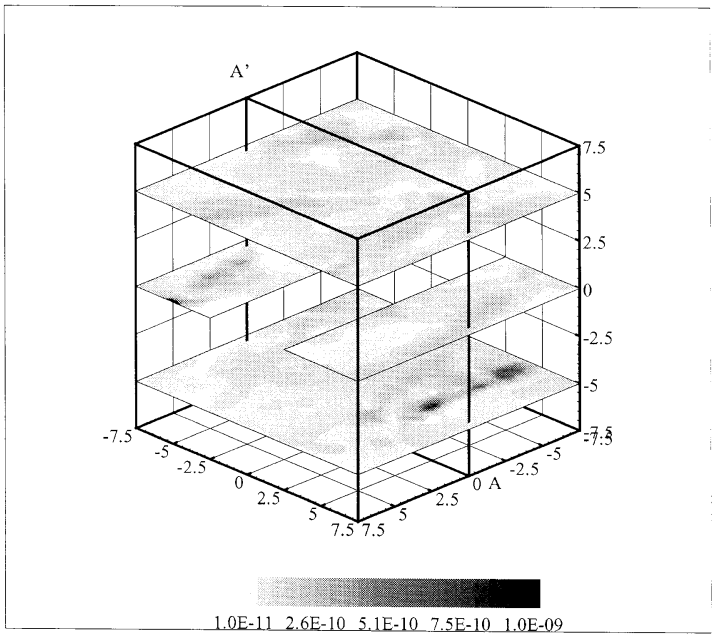

(a)

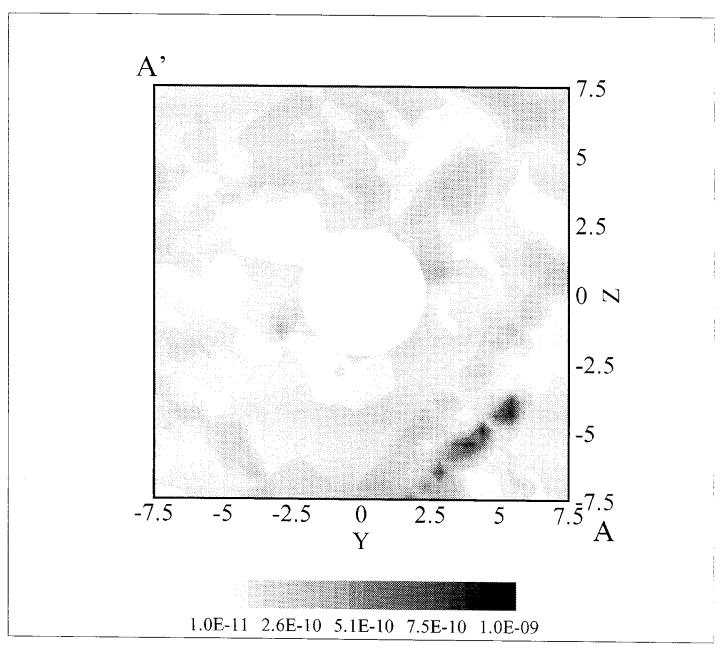

(c)

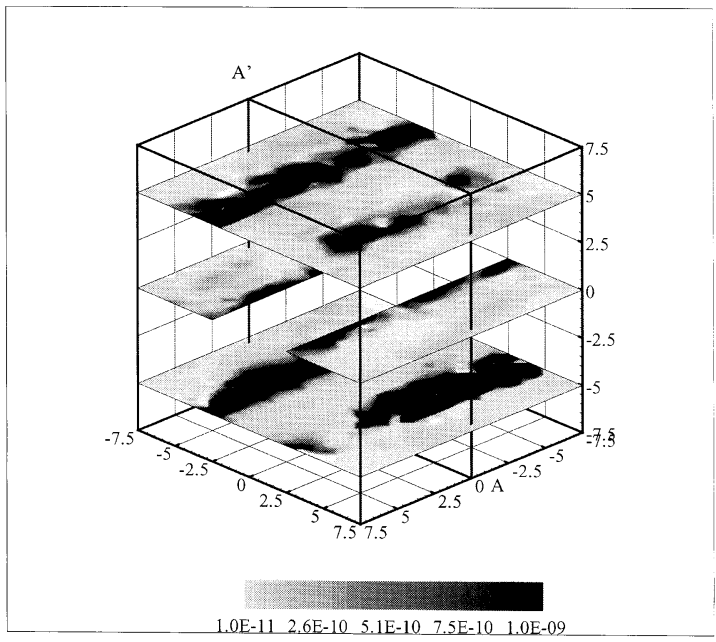

(b)

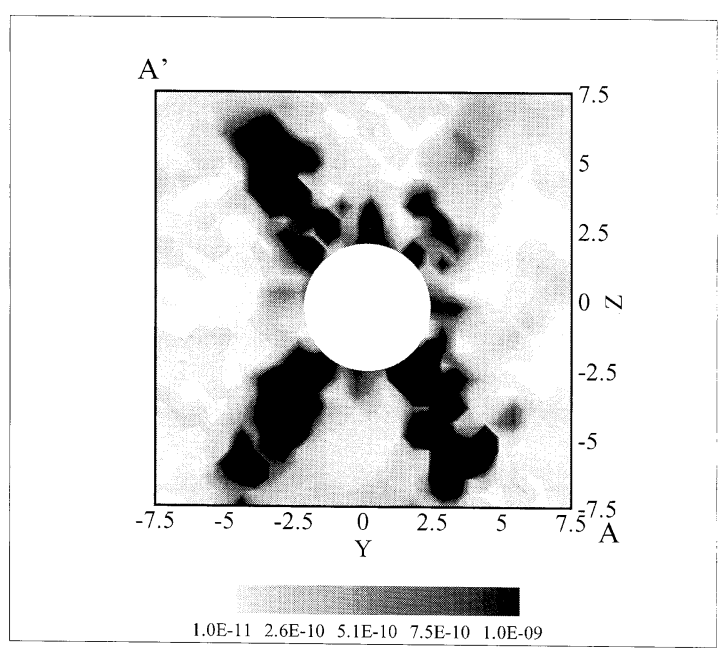

(d)

Fig. 14. Representative transmissivity distribution around the excavation, case 1 (darker regions indicate the zones of higher transmissivity): (a) without excavation effect (top, left), (b) excavation-induced (top, right), (c) without excavation effect, on the cutting plane of $A_{-} A^{\prime}$ (bottom, left) and (d) excavation-induced, on the cutting plane of $A-A^{\prime}$ (bottom, right)

analysis and the joint size in the discrete joint network model analysis is an issue still to be solved.

\section{TEST SIMULATION AND RESULTS}

\section{Mechanical Conditions of Simulations}

A circular tunnel with a diameter of $5 \mathrm{~m}$ is assumed to be located at a depth of $700 \mathrm{~m}$. The tunnel axis is assumed to be aligned to the north. The numerical model measures $50 \mathrm{~m} \times 50 \mathrm{~m} \times 50 \mathrm{~m}$, and the vertical load applied to is equivalent to the overburden weight of the jointed rock mass. The horizontal load, which is determined proportional to the vertical load, is given in Table 1. The model contains two sets of joints, which are inclined in opposite directions. Those joint sets are assumed to have the strikes parallel to the tunnel axis for demonstration purpose. Parameters assigned for the MBC model analysis are shown in Table 1.

\section{Flow Boundary Conditions around Excavation}

Jointed rock masses, measuring $15 \mathrm{~m} \times 15 \mathrm{~m} \times 15 \mathrm{~m}$, are cut out from the original problem because of the numerical limitation on conducting discrete network model analysis. Then the discrete network containing two sets of joints is generated in the jointed rock mass. In the present simulation, 100 realizations of the discrete network are generated for each case of flow simulations. The distributions and parameters used in generating joints are shown in Table 2. One of the examples of the discrete networks obtained using the parameters for case $\# 1$ is shown in Fig. 10. A circular tunnel with a diameter of $5 \mathrm{~m}$ is located in the center of the model. The axis of the tunnel is parallel to the $x$-axis (N-S direction) as in Fig. 11. Figure 11 also shows two different flow boundary conditions to be used.

In the case of a radial flow that might be equivalent to the condition under excavation, following flow boundary conditions are assigned to the flow domain (Fig. 11(a)): 


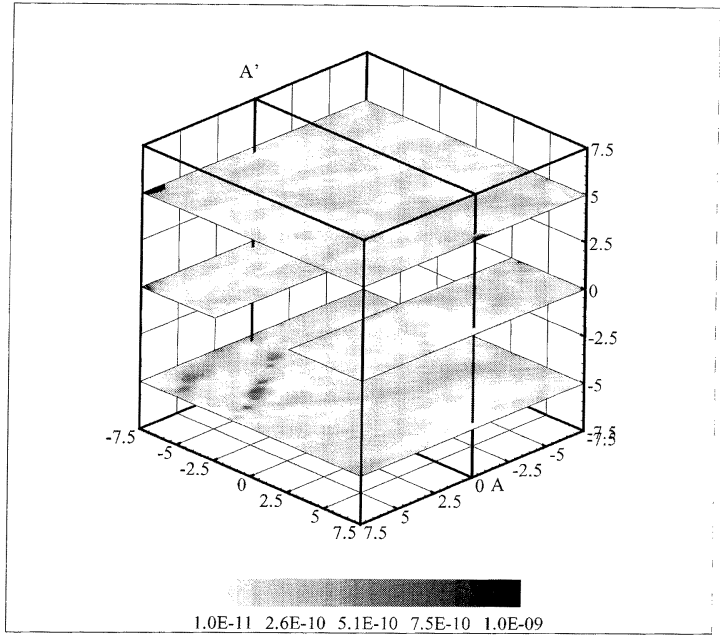

(a)



(c)

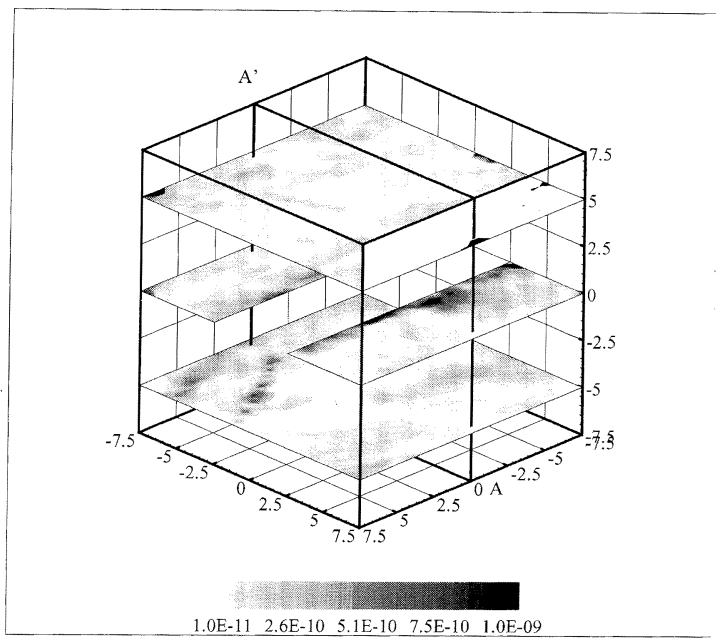

(b)

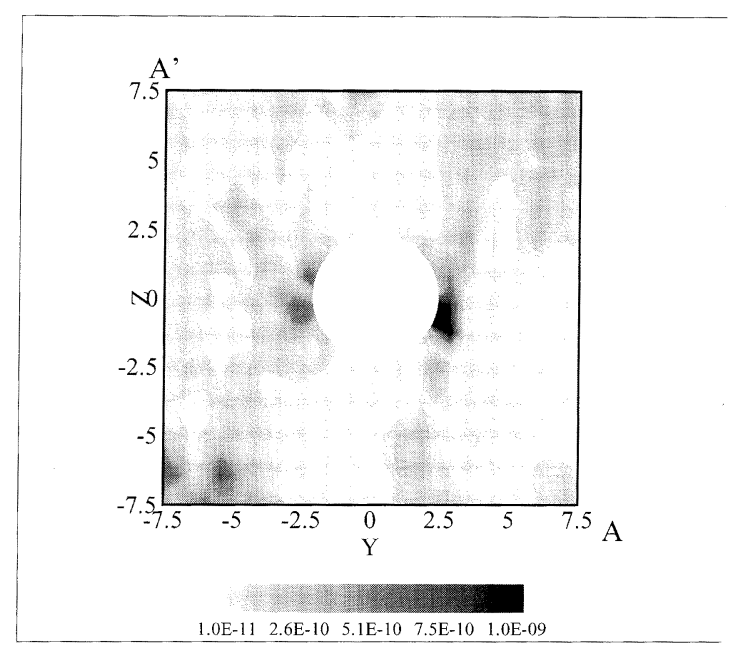

(d)

Fig. 15. Representative transmissivity distribution around the excavation, case $\# 2$ (darker regions indicate the zones of higher transmissivity): (a) without excavation effect (top, left), (b) excavation-induced (top, right), (c) without excavation effect, on the cutting plane of $A_{-} A^{\prime}$ (bottom, left) and (d) excavation-induced, on the cutting plane of $A-A^{\prime}$ (bottom, right)

(1) No flow boundary on the front $(x=7.5 \mathrm{~m})$ and rear $(x=-7.5 \mathrm{~m})$ planes of external cube

(2) Constant but comparatively higher head $(1.025 \mathrm{~m})$ on the other 4 planes of external cube

(3) Constant but comparatively lower head (1.000 m) on the inner circular tunnel boundary

In the case of a linear flow that is parallel to tunnel axis, which may correspond to the condition after a repository is closed and sealed, following flow conditions are imposed (Fig. 11(b)):

(1) No flow boundary on the inner circular boundary and the 4 planes of external cube parallel to flow direction

(2) Constant but comparatively higher head (1.025 m) on the rear plane of external cube

(3) Constant but comparatively lower head $(1.000 \mathrm{~m})$ on the front plane of external cube

The head difference in both of the flow boundary conditions is just $0.025 \mathrm{~m}$, which is low enough to be neglect- ed in estimating effective stresses.

\section{Results and Discussion}

Shear Displacement and Normal Stress around Excavation

Figures 12 and 13 indicate the shear displacement induced and normal stress imposed on joint surfaces around the excavation tunnel under the two different cases. These cases mainly differ in the dip angles for the joint sets, and in the stress ratio defined by the horizontal in-situ stress over the vertical stress. The conditions are selected to simulate the conditions at which shear sliding of joints is easy or unlikely to occur, respectively. It is noted that for the vertically inclined joints sets and under comparatively large horizontal in-situ stresses (case \#2), the excavation-induced shear displacement is limited to narrow regions around the excavation. On the other hand, in the case of relatively horizontally inclined joint sets under lower horizontal in-situ stresses (case \#1), the 


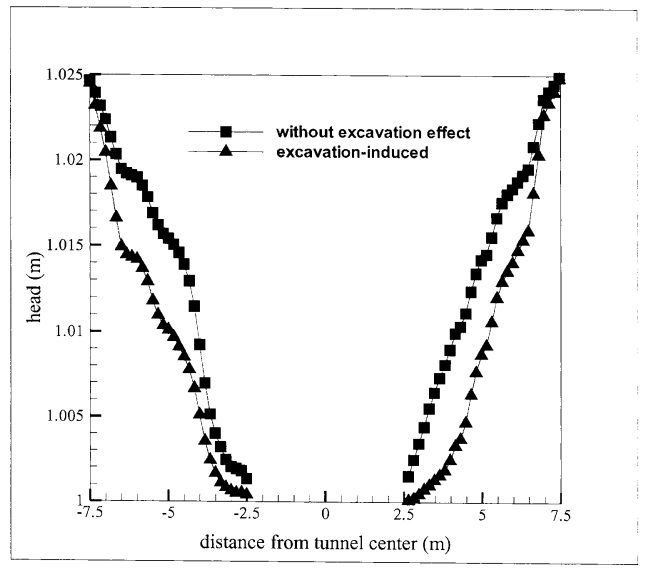

(a)

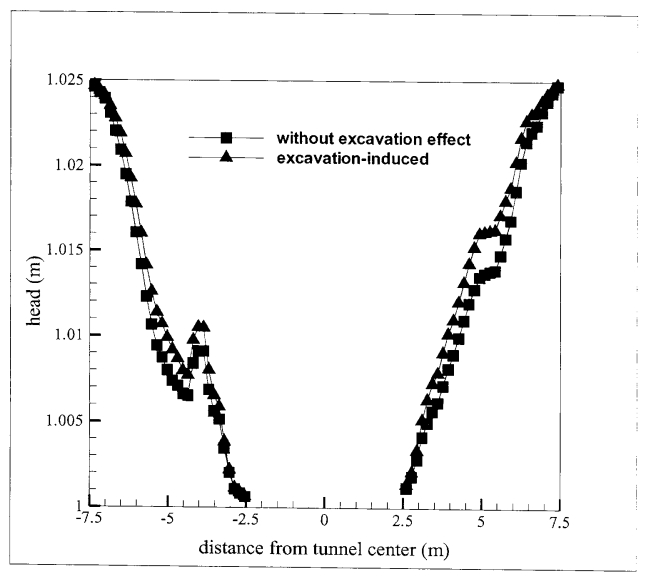

(c)



(b)

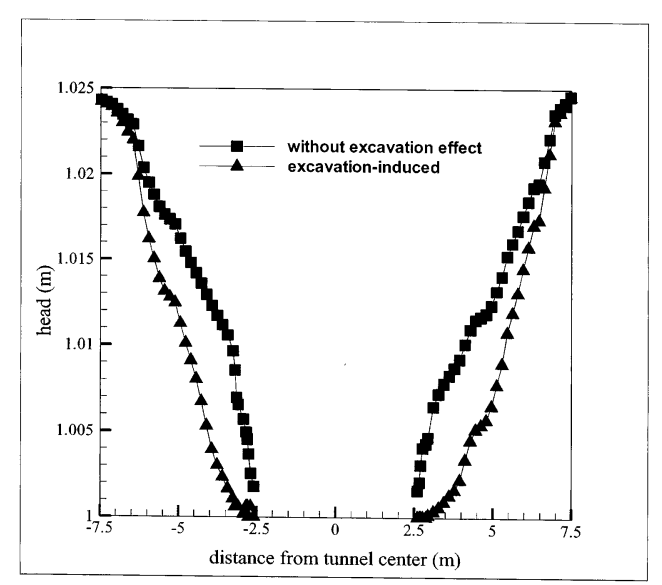

(d)

Fig. 16. Representative head distribution around the excavation on the cutting plane of $A-A^{\prime}:$ (a) top and bottom for case 1 (top, left), (b) side walls for case 1 (top, right), (c) top and bottom for case $\# 2$ (bottom, left) and (d) side walls for case $\#$ (bottom, right)

shear displacement on the joints are considerable up to the depth of the diameter of the tunnel. Concerning the normal stresses acting on the joint surfaces, relatively darker distribution is observed in case $\# 2$ than in case $\# 1$, which indicate the fact that the stress level is considered lower all around the EDZ in case \#2 than in case \#1. From the result, if the hydraulic transmissivity of joints are estimated just using the normal stresses imposed on the joint surfaces, one might get higher overall conductivity of the jointed rock mass from case $\# 2$ than from case $\# 1$. However, as is mentioned later, completely opposite result is obtained, when we take into account of the effect of the shear displacements in the joints.

\section{Transmissivity Distribution around Excavation}

Figures 14 and 15 indicate one of the transmissivity distributions around the excavation tunnel. In a discrete network model, flow occurs through the individual joints and non-zero transmissivities are existed only at the points where the joints are located. However, the interpolation of the transmissivities is conducted within the entire 3-d model space for the purpose of visualization in Figs. 14 and 15.

The excavation induced transmissivities vary as a function of the shear displacement and the normal stress induced by the excavation. The excavation induced transmissivities are significantly increased at the regions where shear sliding occurs (Fig. 14). On the contrary, no appreciable variation is observed in Fig. 15, except for the increase at the side walls near the tunnel. The slight decrease of the transmissivity can be noticed at the roof and floor regions around the tunnel in Fig. 15, since normal stress increment is more predominant than shear sliding deformation.

\section{Head Distribution around Excavation}

The representative hydraulic head profiles for the same realization as previous one in radial flow around the excavation are shown in Fig. 16. The predicted excavation-induced head can be either decreased or increased according to the increase or the decrease of transmissivities and their spatial distribution around the excavation. It is noted that the head predicted with the excavation effect is decreased at the side walls where shear sliding can be observed, but somewhat increased at the roof and floor of the excavation where comparatively small excavation-induced transmissivities are present (in the condition of case \#2). Either decrease or increase of 


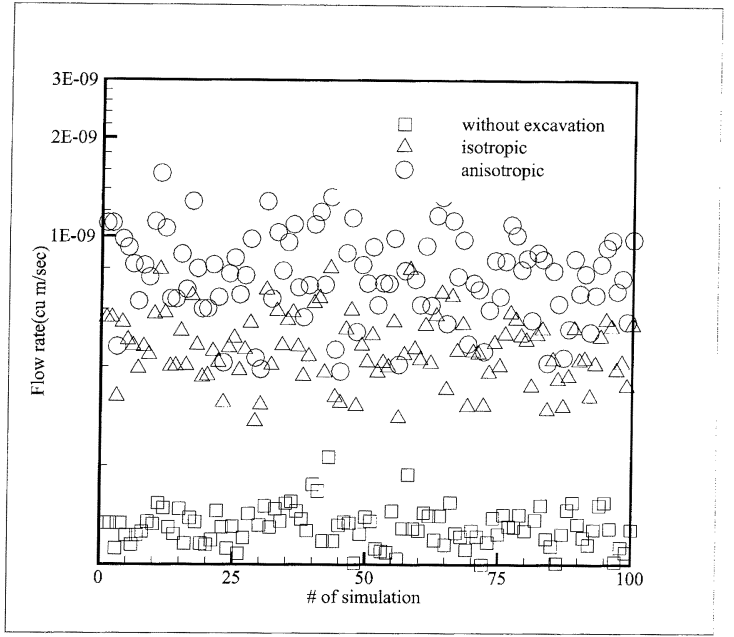

(a)

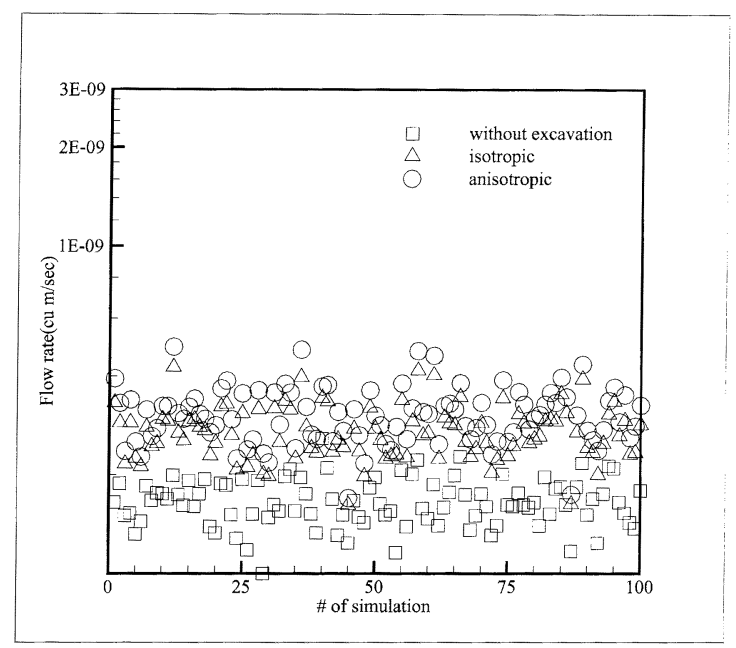

(b)

Fig. 17. Distributions of the predicted flow rate for 100 different realizations of network; The vertical axis is the logarithm of flow rate; It is noted that excavation-induced variation in the flow rate is much greater in axial flow condition: (a) axial flow and (b) radial flow

hydraulic head after the excavation can be simulated, and the rate of variation is different depending on the field conditions and the locations at which the excavation-induced shear displacement and normal stress may differ.

Permeability of Jointed Rock Mass

Permeability of the jointed rock mass is represented by the total flow rate through the model. Figure 17 indicates the distribution of the flow rate obtained from the 100 realizations of discrete networks for case \#1. The movement of the distribution upward means the increase in flow rate. To clarify the effect of anisotropy induced in the joint transmissivity, the results of the numerical simulations with isotropic transmissivity are also plotted in Fig. 17. The isotropic transmissivity is obtained by taking the average of the two principal components of the transmissivity tensor. In Fig. 17, it can be seen that

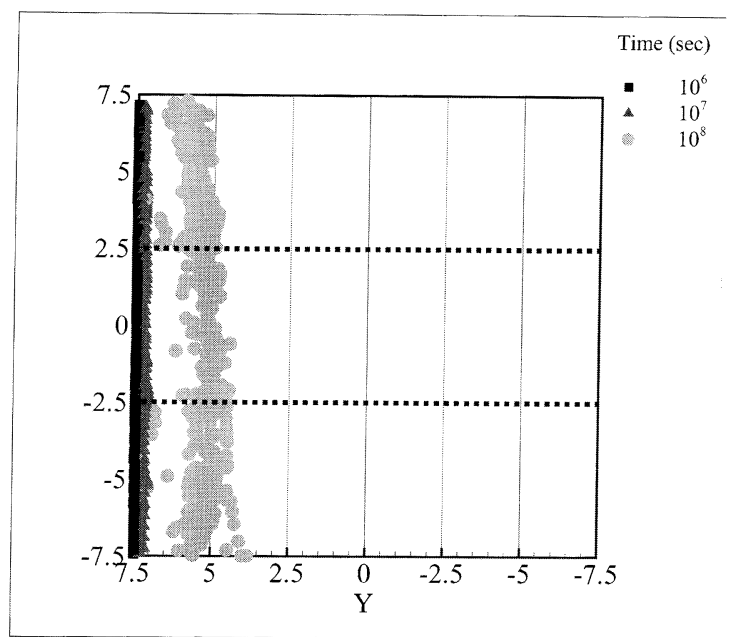

(a)

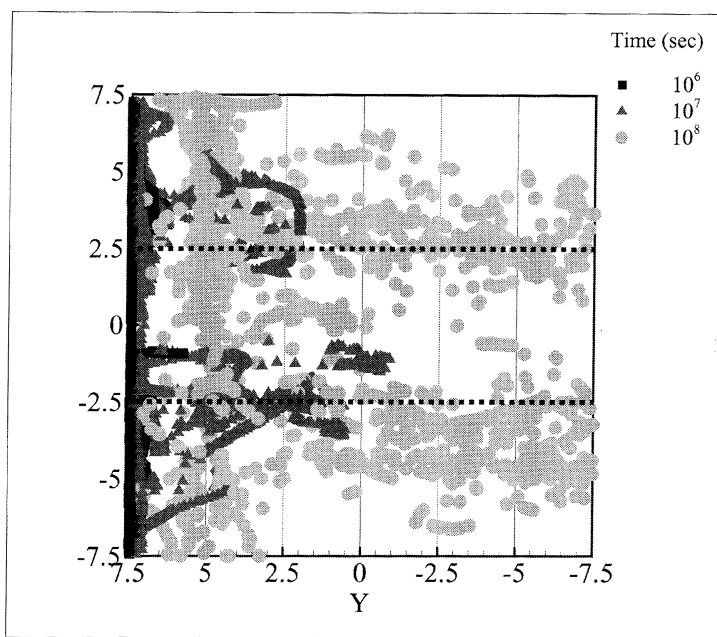

(b)

Fig. 18. Particles remaining within the flow domain after a certain elapsed time step; The dotted lines indicate walls of excavation tunnel: (a) without excavation induced effect and (b) with excavation induced effect

excavation-induced flow rate can be significantly enhanced, especially in the case of the axial flow. This is basically because the joints are mostly parallel to the tunnel axis so that comparatively higher shear deformation is induced in joint transmissivities. As is mentioned above, a higher shear displacement will cause a higher anisotropy in the direction perpendicular to the shear displacement, which is parallel to the tunnel axis in this case. Such a high axial flow around the excavation has been frequently shown in previous publications as well (Pusch, 1987; Hokmark, 1998; Backblom and Martin, 1999).

\section{Particle Transport Time}

Figures 18 and 19 illustrate the results of the representative particle transport simulation for case \#1. Particles are transferred by only advective flow from front to rear plane of the axial flow domain (Fig. 11(b)). In the present 


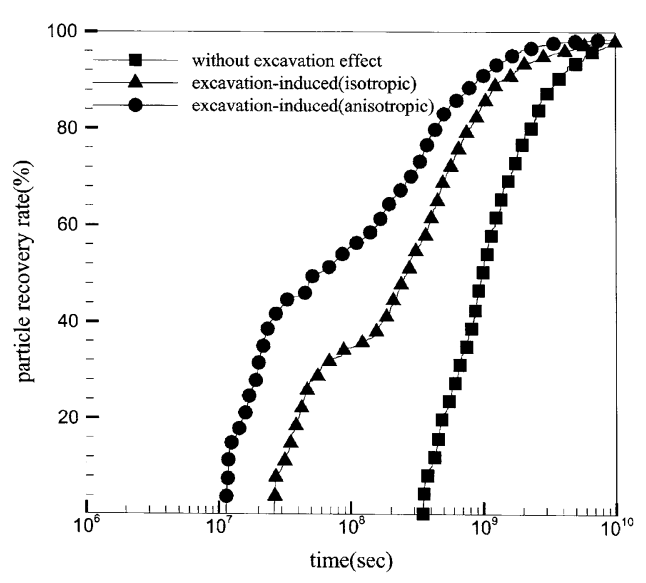

Fig. 19. Particle breakthrough curves indicating the particle recovery rate as a function of the elapsed time after the injection

study, the effect of dispersion and absorption is neglected for simplicity, hence only the effect of hydraulic conductivity is to be discussed.

In general, a dominant flow route is created in a network of joints, and particle transports can be concentrated along this route. In Fig. 18, particle locations within the domain at certain time steps are visualized. From the figure, it can be seen that much faster movement of particles around the excavation can be clearly observed when the excavation induced transmissivity is considered as expected.

Typical particle breakthrough curves, which are defined by the particle recovery rate and the elapsed time, are shown in Fig. 19. In the figure, particle breakthrough curve obtained by assuming isotropic transmissivities for each joints is also plotted, in order to clarify the effect of anisotropy induced by shear deformation. It can be also seen that the first arrival time of particles corresponding to the intersection of the curves with the horizontal axis is significantly reduced not only by the excavation effect but also the anisotropy of transmissivity in the joints.

\section{CONCLUSION}

In the present work, the method to evaluate the hydraulic response of a jointed rock mass to the redistribution of in-situ stresses induced by an excavation is proposed. The proposed method is composed of the Micromechanics-Based Continuum (MBC) model analysis for the excavation analysis and the discrete network model for the flow analysis in a jointed rock mass. By connecting two different codes with the separately implemented computational module which modifies the transmissivities of individual joints into the excavation induced ones in the flow computation. The excavation induced change in the hydraulic properties of a jointed rock mass is evaluated from the analytical approximation solution developed for the flow through a single rough joint.

The characteristics of the current approach are that the surface geometry of a rough joint is fully considered in the calculation of the aperture distribution and that not only the magnitude but also the anisotropy in joint transmissivity induced by shear sliding is incorporated.

In the test simulation, location dependent increase or decrease of transmissivity, significant increment in axial flow rate and particle transport could be observed due to the excavation. It can be seen that the present approach can be effectively used in the analysis of near-field scale, where stress dependent transmissivity of individual joints should be treated discretely. However, it should be noted that, since the simulation condition is virtual, the results presented here cannot be compared with real situation, and thus only a qualitative discussion can be made. Quantitative validation of the proposed method should be conducted by comparing the measured hydraulics of rock mass before and after the excavation.

\section{ACKNOWLEDGMENTS}

We would like to thank Prof. Hidenori Yoshida from the Dept. of Safety System Construction Eng. at Kagawa University, Japan for his help in conducting the MBC model analysis.

\section{REFERENCES}

1) Adler, P. and Thovert, J. (1999): Fractures and Fracture Networks, Kluwer Academic Publishers, Dordrecht/Boston/London.

2) Backblom, G. and Martin, C. (1999): Recent experiments in hard rocks to study the excavation response: implications for the performance of a nuclear waste geological repository, Tunnelling and Underground Space Technology, 14 (3), 377-394.

3) Barton, N., Bandis, S. and Bakhtar, K. (1985): Strength, deformation and conductivity coupling of rock joints, Int. J. Rock Mechanics and Mining Science, 22 (3), 121-140.

4) Beran, M. (1968): Statistical Continuum Theories, Wiley-Interscience, New York.

5) Brown, S. (1987): Flow through rock joints: The effect of surface roughness, J. Geophysical Research, 92 (B2), 1337-1347.

6) Brown, S. and Bruhn, R. (1998): Fluid permeability of deformable fracture networks, J. Geophysical Research, 103 (B2), 2489-2500.

7) Cai, M. and Horii, H. (1992): A constitutive model of highly jointed rock masses, Mechanics of Materials, 13, 217-246.

8) Chen, Z., Narayan, S., Yang, Z. and Rahman, S. (2000): An experimental investigation of hydraulic behavior of fractures and joints in granite rock, Int. J. Rock Mechanics and Mining Science, 37, 1061-1071.

9) Council, N. R. (1996): Rock Fracture and Fluid Flow: Contemporary Understanding and Applications, National Academy Press, Washington.

10) Esaki, T., Du, S., Mitani, Y., Ikusada, K. and Jing, L. (1999): Development of a shear-flow test apparatus and determination of coupled properties for a single rock joint, Int. J. Rock Mechanics and Mining Science, 36, 641-650.

11) Gentier, S., Hopkins, D. and Riss, J. (2001): Dynamics of Fluids in Fractured Rock, American Geophysical Union, Ch. Role of fracture geometry in the evolution of flow paths under stress.

12) Gentier, S., Lamontagne, E., Archambault, G. and Riss, J. (1997): Anisotropy of flow in fracture undergoing shear and its relationship to the direction of shearing and injection pressure, Int. J. Rock Mechanics and Mining Science, 34 (3-4), 258.

13) Hokmark, H. (1998): Numerical study of the performance of tunnel plugs, Engineering Geology, 49, 327-335.

14) Horii, H. and Nemat-Nasser, S. (1983): Overall moduli of solids with microcracks: Load-induced anisotropy, J. Mechanics and 
Physics of Solids, 31, 155-171.

15) Horii, H. and Yoshida, H. (1994): Constitutive modeling of rock masses containing fracturing joints and analysis of large scale excavations, Rock Mechanics: Models and Measurements Challenges from Industry-Proc. 1st North American Rock Mechanics Symposium, 681-688.

16) Hudson, J., Stephansson, O., Andersson, C., Tsang, J. and Jing, L. (2001): Coupled t-h-m issues relating to radioactive waste repository desing and performance, Int. J. Rock Mechanics and Mining Science, 38, 143-161.

17) Inoue, J. and Sugita, H. (2003): Fourth order approximation of fluid flow through rough-wall rock fracture, Water Resources Research, 39 (8), 1202 doi:10.1029/2002WR001411.

18) Jing, L., Stephansson, O., Knight, L., Kautsky, F. and Tsang, C. (1999): Decovalex ii project; technical report-task 1c. Tech. rep., Swedish Nuclear Power Inspectorate.

19) Kelsall, P., Case, J. and Chabannes, C. (1984): Evaluation of excavation-induced changes in rock permeability, Int. J. Rock Mechanics and Mining Science, 21 (3), 123-135.

20) Kim, H. (2002): Evaluation of the hydraulic characteristics of jointed rock mass based on excavation-induced permeability of single rock joint, Ph.D. Thesis, The University of Tokyo.

21) Kim, H. and Inoue, J. (2003): Analytical approach for anisotropic permeability through single rouch rock joint under shear deformation, J. Geophysical Research, 108 (B5), 2366 doi:10.1029/ 2002JB002283.

22) Makurat, A., Barton, N., Rad, N. and Bandis, S. (1990): Rock Joints, Balkema, Ch. Joint conductivity variation due to normal and shear deformation, 535-540.

23) Meheust, Y. and Schmittbuhl, J. (2001): Geometrical heterogeneities and permeability anisotropy of rough fractures, J. Geophysical Research, 106, 2089-2102.
24) Moreno, L. and Tsang, C. (1994): Flow channeling in strongly heterogeneous porous media-a numerical study, Water Resources Research, 30 (5), 1421-1430.

25) Mourzenko, V., Galamay, O., Thovert, J. and Adler, P. (1997): Fracture deformation and influence on permeability, Physical Review, E56 (3), 3167-3184.

26) Olsson, R. and Brown, S. (1993): Hydromechanical response of a fracture undergoing compression and shear, Int. J. Rock Mechanics and Mining Science, 30, 845-851.

27) Pusch, R. (1987): Alteration of the hydraulic conductivity of rock by tunnel excavation, Int. J. Rock Mechanics and Mining Science, 26 (1), 79-83.

28) Pyrak-Nolte, L., Nolte, D., Myer, L. and Cook, N. (1990): Rock Joints, Balkema, Ch. Fluid flow through single fractures, 535-540.

29) Raven, K. and Gale, J. (1985): Water flow in a natural rock fracture as a function of stress and sample size, Int. J. Rock Mechanics and Mining Science, 22 (4), 251-261.

30) Tsang, Y. and Tsang, C. (1989): Flow channeling in a single fracture as a two-dimensional strongly heterogeneous permeable medium, Water Resources Research, 25 (9), 2076-2080.

31) Tsang, Y. and Witherspoon, P. (1981): Hydromechanical behavior of a deformable rock fracture subject to normal stress, $J$. Geophysical Research, 86 (B10), 9287-9298.

32) Yeo, I., deFreitas, M. and Zimmerman, R. (1998): Effect of shear displacement on the aperture and permeability of a rock fracture, Int. J. Rock Mechanics and Mining Science, 35, 1051-1070.

33) Yoshida, H. and Horii, H. (2004): Micromechanics-based continuum model for a jointed rock mass and excavation analysis of a large-scaled cavern, Int. J. Rock Mechanics and Mining Science, 41, 119-145.

34) Zimmerman, R. and Bodvarsson, G. (1996): Hydraulic conductivity of rock fractures, Transport in Porous Media, 23, 1-30. 